\title{
Disability Insurance, Population Health and Employment in Sweden*
}

\author{
Lisa Jönsson, ${ }^{\dagger}$ Mårten Palme ${ }^{\ddagger}$ and Ingemar Svensson ${ }^{\S}$
}

November, 2010

\begin{abstract}
This paper describes the development of population health and disability insurance utilization for older workers in Sweden and analyses the relation between the two. We use three different measures of population health: (1) the mortality rate (measured between 1950 and 2009); (2) the prevalence of different types of health deficiencies obtained from Statistics Sweden's Survey on Living Conditions (ULF, 1975-2005); (3) the utilization of health care from the inpatient register (1968-2008). We also study the development of the relative health between disability insurance recipients and non-recipients. Finally, we study the effect of the introduction of less strict eligibility criteria for older workers in 1970 and 1972 as well as the subsequent abolishment of these rules in 1991 and 1997, respectively.
\end{abstract}

Keywords: Disability insurance, Population health

JEL Codes: H51; H55; I1 8; J26

\footnotetext{
* This paper is a part of the National Bureau of Economic Research project International Social Security. We are grateful to Agneta Kruse and Peter Skogman Thoursie as well as participants on seminars at the ISS meeting for comments on previous drafts of the paper. We gratefully acknowledge financial support from the Bank of Sweden Tercentenary Foundation, the Swedish Council for Working Life and Jan Wallander and Tom Hedelius' Foundation.

${ }^{\dagger}$ Department of Economics, Stockholm University, SE-106 91 Stockholm Sweden and IFAU. E-mail:

Lisa.Jonsson@ne.su.se.

*Department of Economics, Stockholm University, SE-106 91 Stockholm Sweden. E-mail: Marten.Palme@ne.su.se.

${ }^{\S}$ Swedish Pensions Agency, Box 38190, 10064 Stockholm, Sweden. E-mail:

Ingemar.Svensson@pensionsmyndigheten.se
} 


\section{Introduction}

Compared to other industrialized countries, a large share of the Swedish population receives support from the disability insurance program (see Gruber and Wise, 2010). In 2009, 20 percent of the males and more than 30 percent of the females in the age group 60-64 received disability benefits. The disability insurance is the most common pathway out of the labor force for those who exit before the normal retirement age. In 2009, the expenditures from this program corresponded to 1.8 percent of GDP.

Despite the extensive usage of the disability insurance, Sweden has a comparatively high employment rate among older workers. About 70 percent of the population aged 55-64 were employed in 2005, as compared to about 50 percent in Germany, 40 percent in Italy and 60 percent in the United States (see Gruber and Wise, 2010). As in most other European countries, however, there has been a dramatic fall in the employment rate of older men in recent decades. For example, the employment rate of males aged 60-64 has decreased from above 80 percent in the early 1960s to slightly above 60 percent today. This development has caused concern in view of future financial burdens of an aging population.

An explanation for the comparatively high employment rate among older workers combined with high disability insurance recipiency is that Sweden does not have a generous early retirement program. Many European countries introduced such programs in the 1970s and 1980s and the large cross-country differences in employment rates among older workers emerged during this period. For some time, however, the disability insurance program in Sweden developed towards an early retirement scheme. From only awarding disability benefits for health reasons in the 1960s, less strict eligibility criteria, especially for older workers, were introduced in the 1970s. These rules were abolished in the 1990s, and since 1997 an impaired work capacity for health reasons is again the sole eligibility criteria for disability benefits.

In this paper, we study to what extent the evolution of disability insurance utilization can be explained by changes in the population health status and by changes in eligibility rules, respectively. We focus on the age group 45-64, which is the most important for the utilization 
of the disability insurance. ${ }^{1}$ We pose three main research questions. First, is there a relationship between disability insurance utilization and the development of population health status in recent decades? Second, did the changes in eligibility rules for older workers affect disability insurance utilization? Third, did the changes in eligibility rules for older workers affect labor market outcomes such as employment and labor-force participation, or where they "crowded out" by the utilization of other income security programs?

Wadensjö (1996) and Hedström (1987) have previously analyzed the effect of changes in eligibility rules of the disability insurance program in Sweden, in particular the introduction of eligibility rules for labor market reasons targeted at older workers in the early 1970s. Karlström et al. (2008) studied the abolishment of the special eligibility rules for older workers in 1997. In this study, we extend the previous literature by considering the full 40 year history of eligibility changes starting in the early 1970s and by relating it to different labor market outcomes. In addition, we put together a comparatively wide set of population health measures and relate the development of these measures to the development of disability insurance utilization in different demographic groups.

Although we strive to have a broad scope for the empirical analysis, we leave out several plausible explanations for the fluctuations in the utilization of the disability insurance. Previous studies have analyzed the effect of economic incentives on the disability insurance in Sweden (e.g. Kruse and Söderström, 1989; Skogman Thoursie, 1999; and Palme and Svensson, 1999 and 2004). Changes in social norms regarding the utilization of the sickness insurance program has been studied by Lindbeck et al. (2009), and should be a plausible explanation also for changes in the utilization of the disability insurance. The implementation of rules may also be affected by administrative policies within the social insurance system. Finally, changes in the demand for labor with disabilities have not yet been properly studied on Swedish data, but it is an interesting topic for further research.

The rest of the paper is organized as follows. Section 2 gives a brief history of the development of the disability insurance program in Sweden. Section 3 describes the development of various population health measures over time. Section 4 describes the development of the utilization of disability insurance and the development of labor market

\footnotetext{
${ }^{1}$ Disability insurance recipiency in younger ages has increased over time, which is a source of concern. In this paper, however, we limit our focus to the utilization of the disability insurance in older ages.
} 
outcomes. Section 5 studies the relation between population health and disability insurance utilization. Section 6 studies the relation between the eligibility reforms for older workers, disability insurance utilization and various labor market outcomes. Section 7 concludes.

\section{Historical overview of the disability insurance in Sweden}

The disability insurance (DI) is one of Sweden's most important income security programs. Its main objective is to replace foregone earnings for workers below the retirement age with a permanently impaired working ability for health reasons. The related sickness insurance replaces foregone earnings due to a temporarily impaired working ability for health reasons. Disability benefits can be granted part time or full time, depending on the extent of the work impairment.

Sweden's disability insurance has a comparatively long history. The first public pension system covering all citizens, including an invalidity pension, was implemented already in 1914. The recent history of Sweden's disability insurance, which we analyze in this paper, started when a public income related supplementary pension scheme (ATP) was introduced, following a referendum in 1957. The new scheme came into place in 1960 and the first payments were made in 1963, but since the program was phased in, it did not reach its full maturity until the beginning of the 1990s. The pension benefit under this scheme replaced 60 percent of the average of an individual's 15 best years of earnings up to a social security ceiling. The benefit was linearly reduced if the worker contributed less than 30 years to the scheme and it was financed through payroll taxes.

The new income related pension also included disability insurance. The size of the individual benefit was calculated in the same way as the old-age pension benefit, with the actual earnings history replaced by an assumed earnings profile. Eligibility for disability benefits was initially based on health. Disability benefits were awarded by the local Social Insurance Agency after a physical examination by a medical doctor. If the health status prevented the worker from doing his or her regular job, but not one that suited the worker's general qualifications, the worker was required to go through a retraining program. 
Eligibility rules for disability benefits changed on several occasions after the new disability insurance was first introduced. Table 1 summarizes the main eras in this history. The first major reform took place in 1970 and had two main components. First, special eligibility rules were introduced for workers aged between 63 and the normal retirement age, the age of 67 at that time. These rules implied that (a) no rehabilitation or retraining for a new occupation was required if the worker's health status did not permit his or her regular work; (b) the medical requirements for assessing inability to work were substantially lower for this age group; and (c) also functional limitations due to normal aging could be considered for eligibility for DI. Second, unemployment was made an additional criterion for DI eligibility in all age groups. Long-term unemployed workers with functional limitations were made eligible for DI after having been unemployed for 1-2 years.

The next reform towards more generous eligibility rules for DI took place in 1972, when pure labor market reasons for older workers were introduced. These rules implied that workers aged between 63 and the normal retirement age could become eligible for DI if they were still unemployed when reaching the time limit in the unemployment insurance, even without any health limitations. In 1974, the age limit for pure labor market reasons was lowered from age 63 to age 60, and in 1976 the age limit for the special eligibility rules for older workers, introduced in 1970, were lowered from age 63 to age 60 . The latter change was partly made as a consequence of the decrease in the normal retirement age from age 67 to 65 in 1976.

Table 1. Changes in eligibility rules for the disability insurance.

\begin{tabular}{lcccc}
\hline Period & $\begin{array}{c}\text { Medical } \\
\text { reasons }\end{array}$ & $\begin{array}{c}\text { Labor market and } \\
\text { medical reasons }\end{array}$ & $\begin{array}{c}\text { Special eligibility } \\
\text { rules for older } \\
\text { combined }\end{array}$ & $\begin{array}{c}\text { Pure labor } \\
\text { market reasons } \\
\text { for older workers }\end{array}$ \\
\hline-1962 & Yes & Very small & No & No \\
1963-1970(June) & Yes & Some & No & No \\
1970(July)-1972(June) & Yes & Yes & Yes, aged 63-66 & No \\
1972(July)-1974(June) & Yes & Yes & Yes, aged 63-66 & Yes, aged 63-66 \\
1974(July)-1976(June) & Yes & Yes & Yes, aged 63-66 & Yes, aged 60-66 \\
1976(July)-1991(Sept) & Yes & Yes & Yes, aged 60-64 & Yes, aged 60-64 \\
1991 (Oct)-1996 & Yes & Yes & Yes, aged 60-64 & No \\
$1997-$ & Yes & Very small & No & No \\
\hline
\end{tabular}


Two changes led to higher replacement levels in the disability insurance during the 1970s and 1980s. First, the maturity of the supplementary pension scheme (ATP) led to higher replacement levels in general. Second, the introduction of a "special supplement" in 1969 led to improvements for low income pensioners. It was reduced on a one-to-one basis against income from the supplementary pension (ATP). The special supplement applied to all types of pension and was gradually increased from 1969 to 1981. In 1977, the amount of the special supplement was doubled for DI pensioners only, and the subsequent development of the supplement for DI beneficiaries followed the gradual increase for regular pensioner but at twice as high a level.

The policy toward more liberal DI eligibility rules was reversed in the 1990s. The eligibility for DI for pure labor market reasons for older workers, introduced in 1972, was abolished in 1991. In 1991 and 1992, a new legislation was also enacted with the purpose of reducing sickness absence, which required employers to improve the work environment and take responsibility for the rehabilitation of employees. The Social Insurance Agencies were made responsible for the coordination of rehabilitation among the employer, the public health care system, labor market authorities, the local government and the individual. In 1997, also the favorable eligibility rules for older workers and the eligibility for DI for labor market reasons and medical reasons combined, introduced in 1970, were abolished. Since then, an impaired work capacity for health reasons has been the only eligibility criterion for disability insurance.

On 1 January 2003, the disability insurance was shifted from the public pension system to the public sickness insurance system, following a major pension reform. Benefits were renamed and the calculation of benefits changed, but the assessment of eligibility remained the same. Benefits were calculated as 64 percent of the assumed income, i.e., the income of the best three of the last five to eight years, depending on age, up to a social security ceiling. Individuals not qualifying for the income related insurance received a guarantee benefit.

From January 2005 onwards a re-assessment of the working capacity for granted individuals should be made every third year. Also in 2005, the organization of the Social Insurance Agency changed, when the 21 regional offices were integrated into one central authority. In 2008, the eligibility for disability benefits was substantially tightened. For all cases granted after 1 July 2008, working capacity had to be permanently reduced in relation to the entire labor market in order to qualify for benefits. 


\section{The development of population health}

Changes in population health would be a natural determinant of the evolution of disability insurance recipiency over time. To describe the development of population health in Sweden over the last decades, we use three main groups of health measures: the mortality rate, selfreported health measures from the Survey on Living Conditions and, finally, the utilization of inpatient care from the National Patient Register. For our purposes, each of the three measures of population health has its obvious advantages and disadvantages.

The main advantage of mortality as a health measure is that it is objective and accurately measured through the population censuses, which makes it easily comparable across countries and time. A disadvantage is that mortality is more of an outcome measure, in part reflecting technological advances within the health care system rather than the average health status of the population. It might also target a slightly inappropriate population for our purposes, since it measures the health of the marginal survivors rather than the marginal workers. Diseases that cause death and diseases that reduce working capacity may be different. Finally, a higher survival rate implies that individuals who would previously have died now survive, although possibly with a bad health status. This could change the composition of the population and in turn affect the average health status negatively although mortality decreases.

The advantage of the self-reported health measures is that they are better targeted towards the aspects of health that are relevant for the ability to remain in the labor force. The main disadvantage relates to the fact that they are subjective. Fluctuations over time might capture changes in the interpretation of the questions and the general view of health rather than changes in actual health. Another disadvantage is that the self-reported health measures may be state dependent. For example, since an impaired work capacity is an eligibility criterion for disability benefits, individuals may be more likely to report an impaired work capacity as a result of receiving benefits.

The advantage of the utilization of inpatient care as a health measure is that it is accurately measured, since it is obtained from registers, and closely related to the health status of the worker. It has, however, the disadvantage of the self-reported measures of being sensitive to changes in the general view of health. Furthermore, the utilization of inpatient care might be 
influenced by public healthcare spending, working procedures at the hospitals and the division of labor between outpatient and inpatient care.

\subsection{Mortality}

The mortality rate is defined as the number of deaths during a year divided by the average size of the population in a particular age group. We present the development of mortality in Sweden in three different ways. Figure 1 shows the development from 1960 to 2009 of the age at which men and women faced the same mortality rate as that which the 60 and 65 year olds faced in 1960. Figure 2 shows the mortality rate by age in 1960 and 2005 for men and women, respectively. Finally, Figure 3 shows the development of the mortality rate for men and women, respectively, at the age of 55, 60 and 65 from 1950 to 2009.

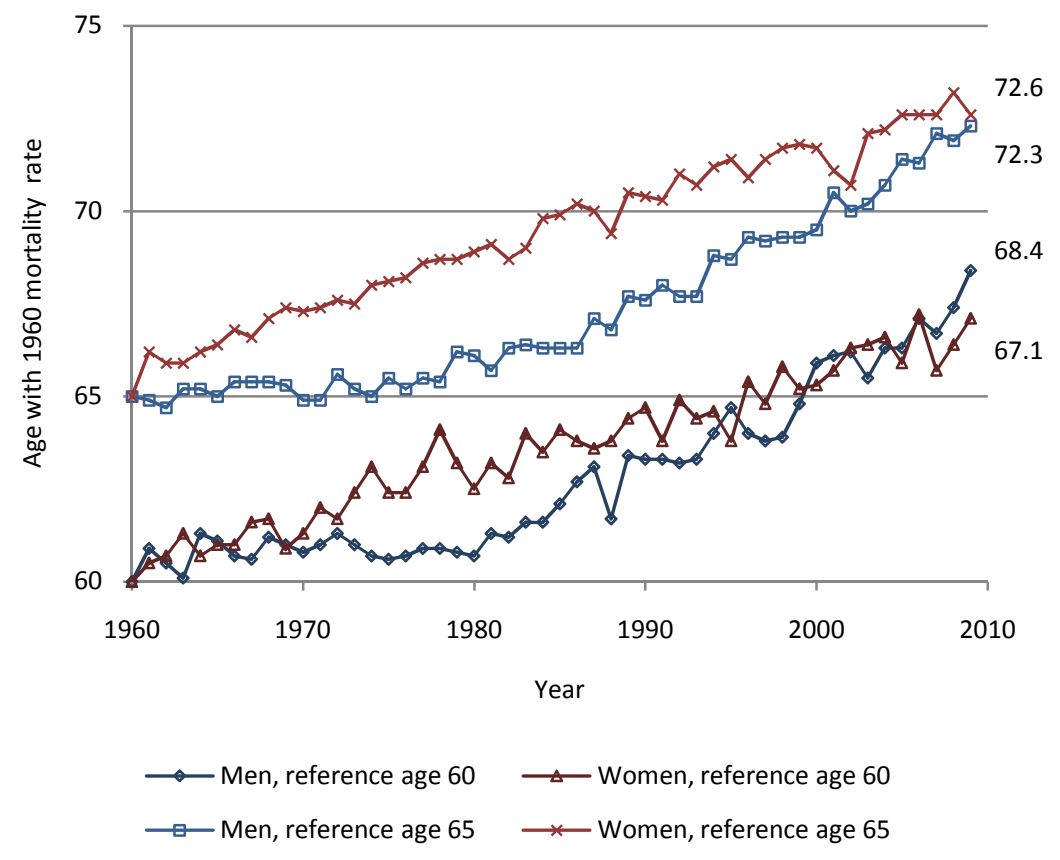

Figure 1. Ages of equal mortality probability, 1960-2009

Source: Statistics Sweden

These figures reveal two interesting results. First, there has been a marked decrease in mortality for both men and women during the period under study. Figure 1 shows that the age of equal mortality as that which the 60 year olds faced in 1960 increased by 8.4 years for men and 7.1 years for women until 2009, and that the age of equal mortality as that which the 65 year olds faced in 1960 increased by about 7.5 years for both genders until 2009. Figure 2 
shows that the age at which the mortality rate passes five percent increased by 5 years for men and 7 years for women between 1960 and 2005. Finally, Figure 3 shows that the mortality rate has halved from 1950 to 2009 for men and women in all age groups.

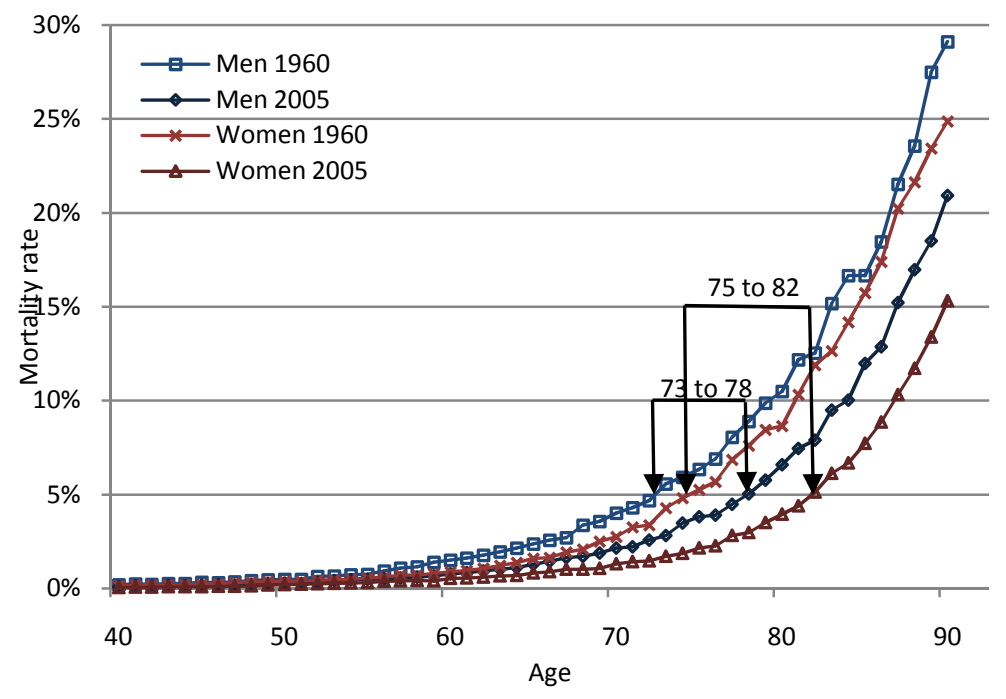

Figure 2. Mortality rates by age, 1960 and 2005

Source: Statistics Sweden

A. Men

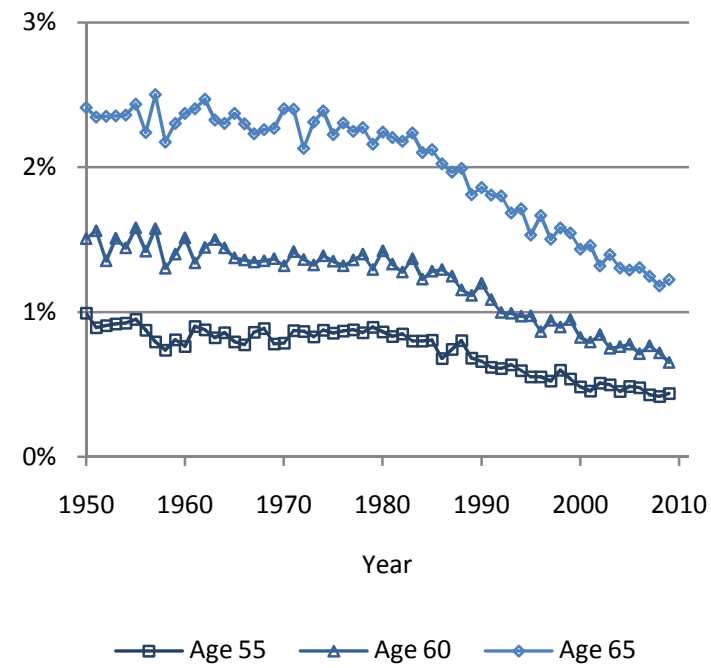

B. Women

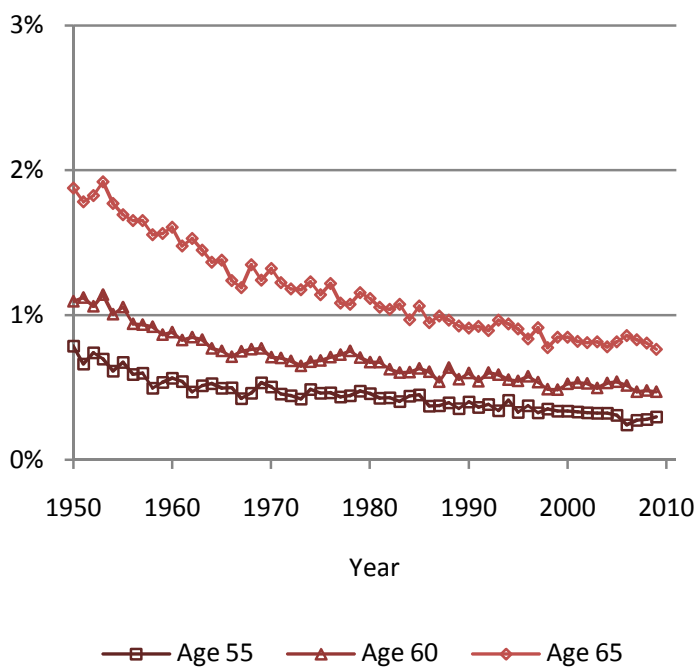

Figure 3. Mortality rates by year, 1950-2009. Source: Statistics Sweden

The second result is that the large decrease in mortality happened much earlier for women.

Figure 3 shows that the mortality rate for 65 year old women decreased from about 2 percent in 1950 to about 1 percent in 1980. Since then, it has decreased by less than 0.25 percentage 
points. Also for women at younger ages, the mortality rate decreased most rapidly before 1980. For men, on the other hand, the main improvement occurred after 1980. Between 1980 and 2009 , the mortality rate for 65 year old men decreased by 1 percentage point to just over 1 percent. Also for younger men, mortality decreased most rapidly during this period. The same pattern is visible in the series of equal mortality probability in Figure 1. The gap between men and women broadened until the mid 1980s, and thereafter narrowed substantially. The development for the youngest males is so steep after 1980 that it even surpasses the development for women in the mid 2000s.

\subsection{Self-reported health}

Self-reported information about the health of the Swedish population is collected by Statistics Sweden through the Survey on Living Conditions (ULF). It is a yearly survey of a random sample of about 7,500 individuals aged 18-64 that has been produced since 1975. The survey contains a large set of questions about health in general as well as about particular diseases. We present the results from the survey for men and women in the age groups 45-54, 55-59 and 60-64. All series show the share of the population in the age group with a certain condition. To reduce the problem of large stochastic errors due to small sample sizes within each demographic group, we present three-year moving averages. We also focus on the longrun development of the series rather than fluctuations in single years.

Figure 4 presents the development of a set of general health indicators from the survey. The indicator "Doctor's visit" shows the share of the population who visited a doctor within the last three months. The indicator "Long-term disease" shows the share of the population with at least one disease in a list of diagnoses and the indicator "Impaired work capacity" shows the share of the population reporting that the long-term disease causes an impaired work capacity. The indicator "Impaired ability to move" shows the share of the population who are not able to run 100 meter. Finally, the indicators "Poor health" and "Good health" show the self-assessed health status, based on a question where the individual evaluates his or her general health on a particular scale. ${ }^{2}$ The mortality rate in each demographic group is included as a comparison.

\footnotetext{
${ }^{2}$ See Statistics Sweden (2009) for more information.
} 
As opposed to the development of mortality, Figure 4 shows no overall trend for the development of the self-reported health indicators over time for neither men nor women. Two of the indicators, the share of the population with a long-term disease and the share of the population that recently visited a doctor, show an adverse or invariant development over time in all demographic groups. Both of these indicators have increased for men and women aged 45-54 and women aged 55-59 and have remained stable for men aged 55-59 and men and women aged 60-64. In general, these two indicators seem to have developed more adversely for women than for men and for younger than for older age groups.

Other self-reported health indicators have developed in opposite directions in different demographic groups. The share of the population with an impaired work capacity has remained stable over time for men aged 45-54 and 55-59, but has decreased by a third for men aged 60-64 since 1976. For women, there is instead an upward trend, in particular for the 45-54 and 55-59 year olds. Also women aged 60-64 show a slight upward trend, implying that the share of women with an impaired work capacity has not developed in the same promising way as the share of men with an impaired work capacity in this age group.

The remaining health indicators show an invariant or advantageous development over time. The health indicator with the most favorable development is the share of the population with an impaired ability to move, which has decreased in all demographic groups. The reduction has been particularly large for men and women aged 60-64, where the share has almost halved over the period. This is the only indicator improving over time for all female age groups.

The share of the population in poor health remained stable for men and women aged 45-54 and women aged 55-59, and decreased slightly for men aged 55-59 and men and women aged 60-64. This broad pattern is supported by the development of the share of the population in good health, which has remained stable for men and women in the age group 45-54 and has improved for the two older age groups. In the age group 60-64, the share of the population in good health has increased from about 55 to 65 percent for both men and women. 
A. Men age 45-54

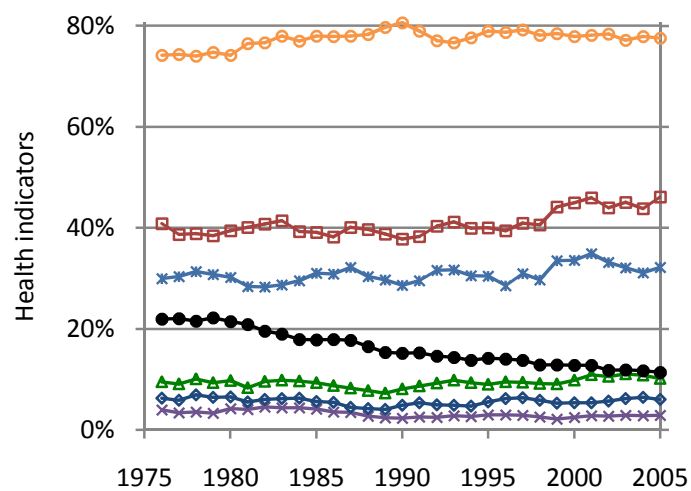

C. Men age 55-59

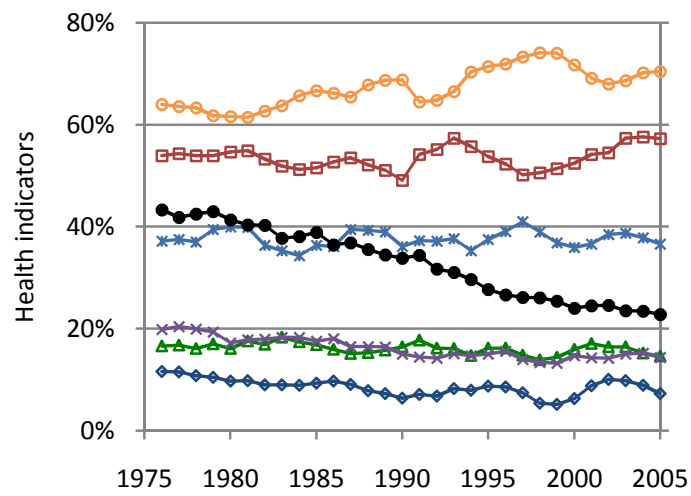

E. Men age 60-64

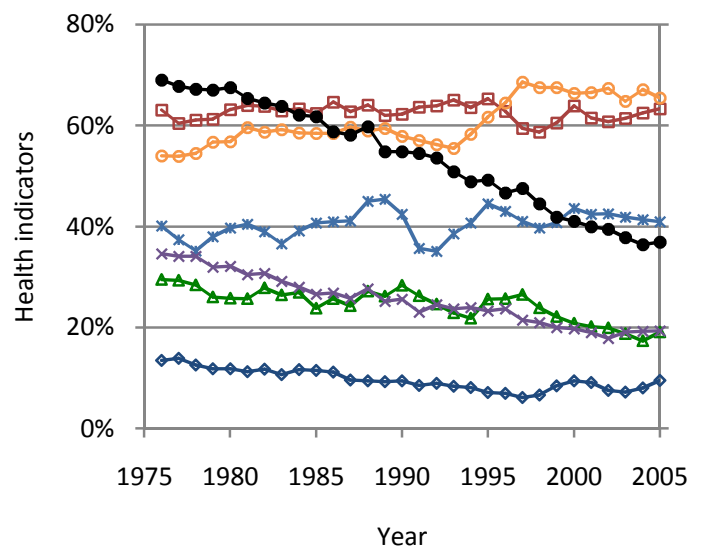

$\longrightarrow$ Doctor's visit
$\multimap$ - Impaired work capacity $\longrightarrow$ Long-term disease
$\multimap$ Impaired ability to move
$\multimap$ Poor health $\quad \longrightarrow$ Good health
$\multimap$ Mortality rate
B. Women age 45-54

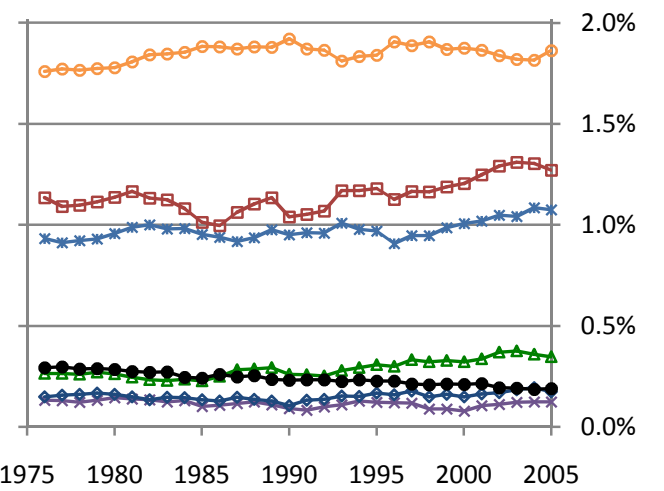

D. Women age 55-59

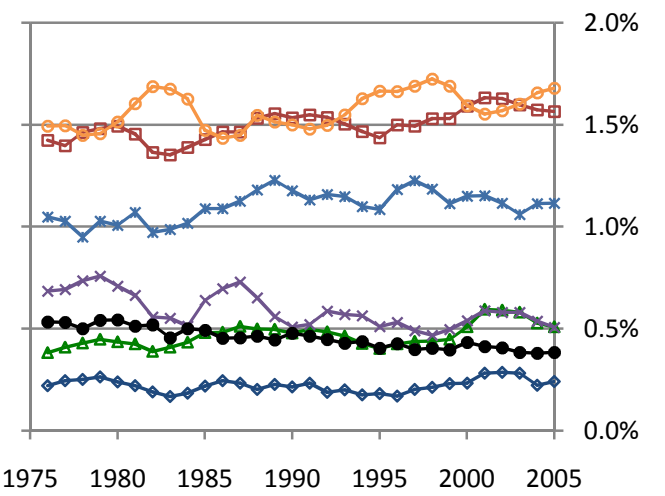

F. Women age 60-64

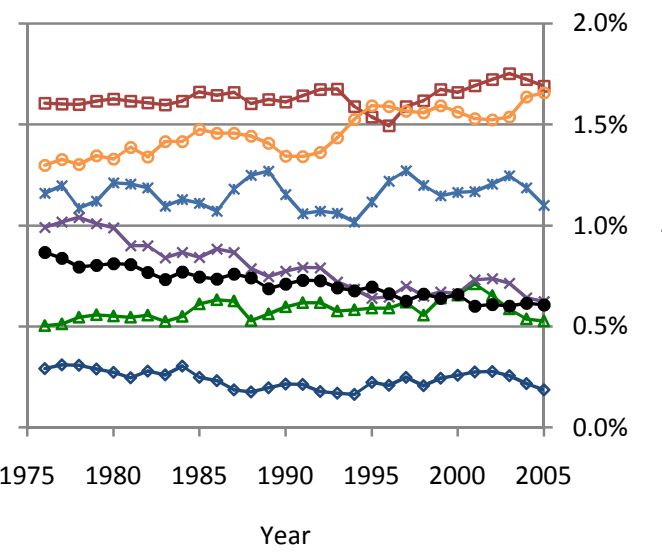

$$
\begin{aligned}
& \text { —-Doctor's visit } \quad \longrightarrow \text { Long-term disease } \\
& \multimap \text { Impaired work capacity — } \\
& \longrightarrow \text { Poorhealth } \quad \longrightarrow \text { Goodhealth } \\
& \longrightarrow \text { - Mortality rate }
\end{aligned}
$$

Figure 4. Self-reported health indicators and mortality, 1976-2005

Source: Statistics Sweden 
A. Men age $45-54$

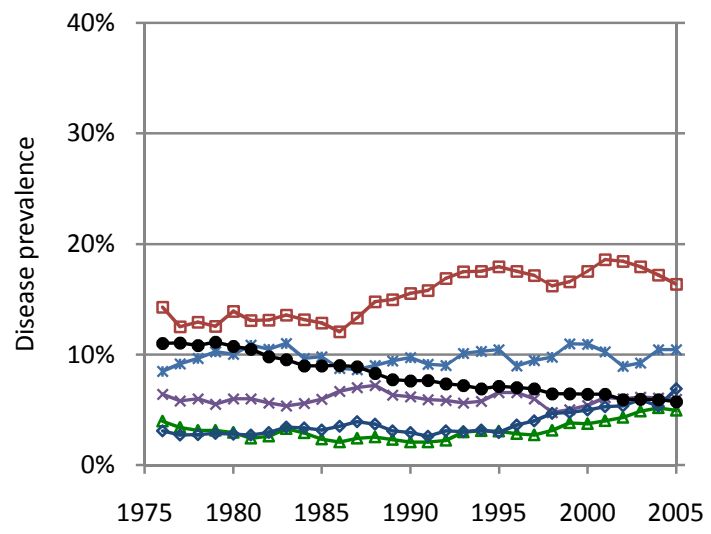

C. Men age 55-59

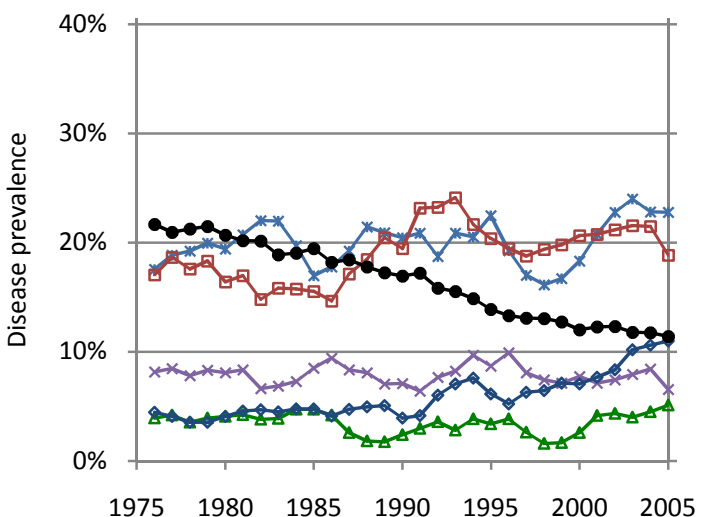

E. Men age 60-64

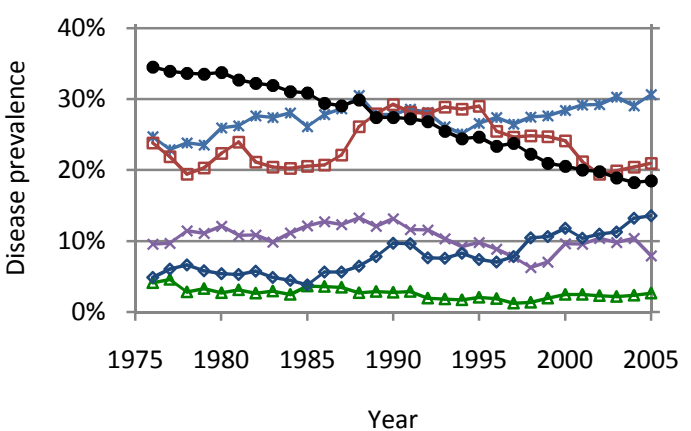

— Circulatory diseases

$\longrightarrow$ Musculoskeletal diseases

$\triangle$ Mental disorders

* Nervous system

$\longrightarrow$ Endocrine diseases

$\longrightarrow$ Mortality rate
B. Women age $45-54$

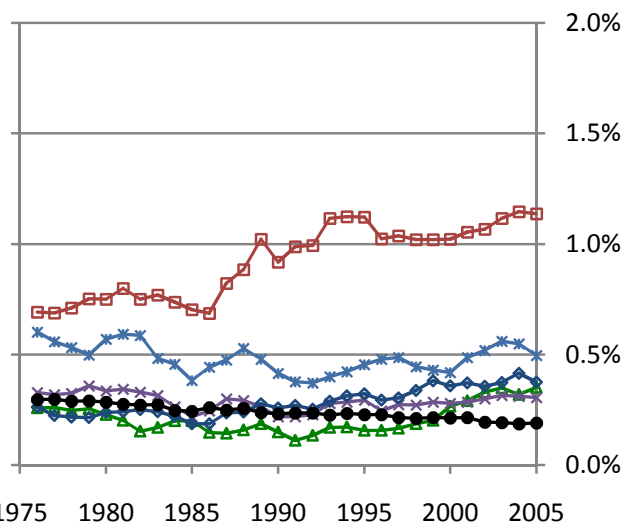

D. Women age 55-59

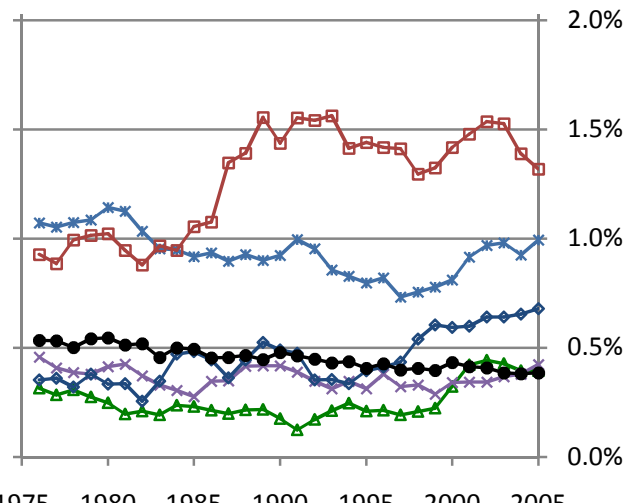

F. Women age 60-64

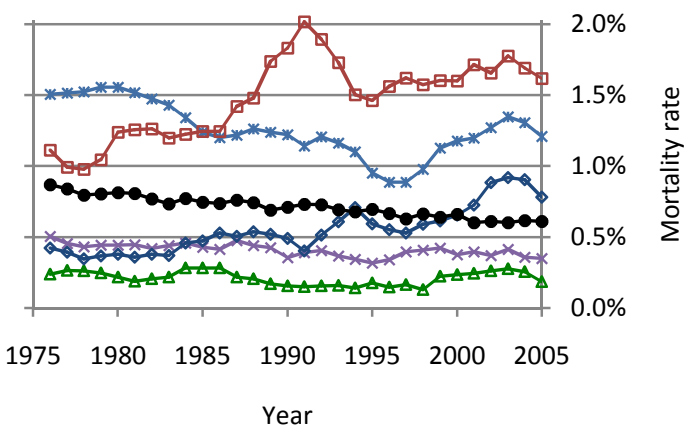

$$
\begin{aligned}
& \longrightarrow \text { Circulatory diseases } \\
& \square-\text { Musculoskeletal diseases } \\
& \square \text { Mental disorders } \\
& \multimap \text { Nervous system } \\
& \multimap \text { Endocrine diseases } \\
& \rightarrow \text { Mortality rate }
\end{aligned}
$$

Figure 5. Self-reported disease prevalence and mortality, 1976-2005

Source: Statistics Sweden 
In addition to the general health indicators, the Survey on Living Conditions contains information about self-reported disease prevalence for a number of diagnoses. Figure 5 shows the development over time for the prevalence of diseases for five diagnosis groups that are of particular importance for the disability insurance. These include circulatory diseases, musculoskeletal diseases, mental disorders, diseases in the nervous system and endocrine diseases. The development of the mortality rate in each demographic group is included as a comparison.

The development of self-reported disease prevalence does not reveal any unambiguous trend. Different diagnosis groups follow different patterns over time. The prevalence of musculoskeletal diseases has increased in all demographic groups, except men aged 60-64, since the mid 1980s. The increase has been particularly striking for women. Also the prevalence of endocrine diseases has increased in all demographic groups since the mid 1980s. This is likely to reflect that problems related to obesity, such as diabetes, have become more common. The prevalence of mental disorders has remained stable for most of the period, but has increased since 1995 in the two youngest age groups. The prevalence of nervous diseases has remained stable for the two youngest age groups and has decreased slightly in the age group 60-64. Although fluctuations in the prevalence of circulatory diseases have been large, there are no clear patterns in the long run.

\subsection{Inpatient care}

The utilization of inpatient care is registered in The National Patient Register at The National Board of Health and Welfare. The register contains all overnight hospital visits in Sweden from 1987 and onwards. For a selection of counties, however, the register contains information from as far back as 1968. To get a longer perspective, we use information about inpatient care for four of Sweden's twenty-one counties from 1968 to 2008 . The presented series show the share of the population in the four counties taken together that experienced at least one overnight hospital visit during the year. ${ }^{3}$

Figure 6 shows the development of inpatient care from 1968 to 2008 for men and women in the three age groups. In the two oldest age groups, the utilization of inpatient care has been

\footnotetext{
${ }^{3}$ The selected counties are Dalarna, Gävleborg, Uppsala and Jämtland. The development of inpatient care in these counties taken together follows that of the entire Sweden from 1987 onwards.
} 
higher for men than for women throughout the period. In the youngest age group, utilization has been very similar across genders, although slightly higher for women. As expected, the utilization of inpatient care increases by age. Over time, the series show a slightly increasing trend in the utilization of inpatient care up to the mid 1980s, followed by a substantial decrease to levels similar to, or even lower than, those in the late 1960s. The decline was much more pronounced for men than for women in the two oldest age groups, which has lead to a convergence in the utilization of inpatient care across genders. This suggests an improvement in the health of men relative to women in these age groups since the mid 1980s, which is consistent with the results from the self-reported health measures and the development of the mortality rates reported previously.

A. Men

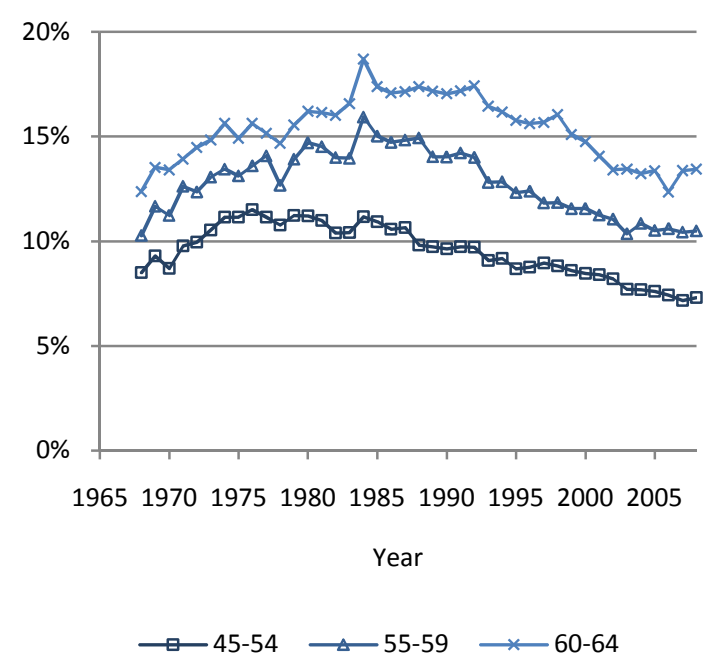

B. Women

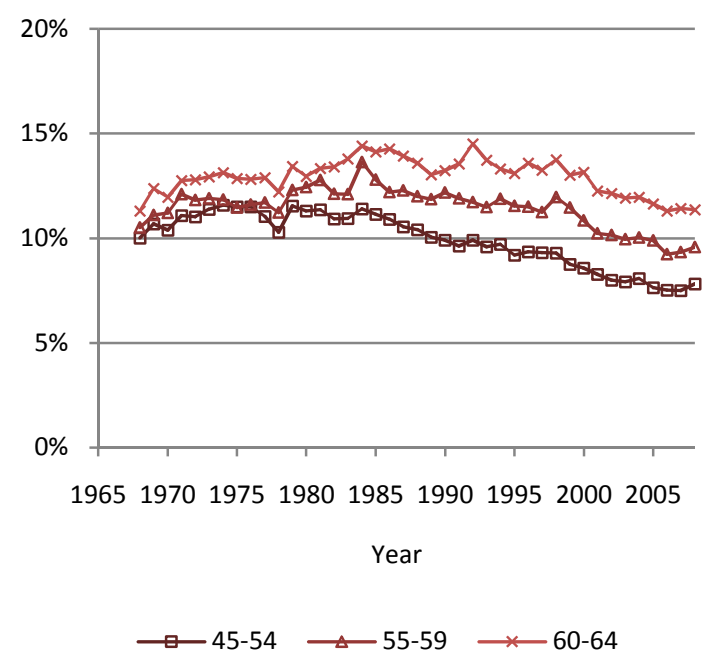

Figure 6. The share of the population receiving inpatient care during the year, 1968-2008 Source: The National Board of Health and Welfare

\subsection{Conclusions about the development of population health}

The three main measures of population health give an ambiguous picture of the development of the general health status in Sweden over the past decades. The development of the mortality rate suggests a marked health improvement over time for both men and women. The development of the self-reported health indicators does, however, not confirm this result. Only men aged 60-64 show an invariant or positive development for all self-reported health indicators over time. Also the development of the utilization of inpatient care does not indicate a clear-cut health improvement over time. 
Two main conclusions emerge from our analysis. First, health seems to have developed more adversely for females than for males since the mid 1970s. Female mortality decreased most rapidly up until the 1970s, while male mortality decreased substantially from 1980 onwards. For the self-reported health measures, we only have information from 1976 onwards. Since then, these measures show a less advantageous development of the health of females than the health of males. The development of the utilization of inpatient care confirms this pattern. Since the early 1980s, the utilization of inpatient care in the two oldest age groups has decreased more for men than for women. The development in the youngest age group, aged 45-54, however, has been similar for men and women.

The second main conclusion is that the health of younger age groups seems to have deteriorated compared to older ones. The self-reported health indicators suggested a worsened health status over time for both men and women in the youngest age group, aged 45-54, whereas the health status of the oldest age group, aged 60-64, improved. This is supported by the development of the mortality rate, where the decline was steeper at age 65 than at ages 55 and 60. It is not apparent, however, in the development of inpatient care utilization.

A. Men

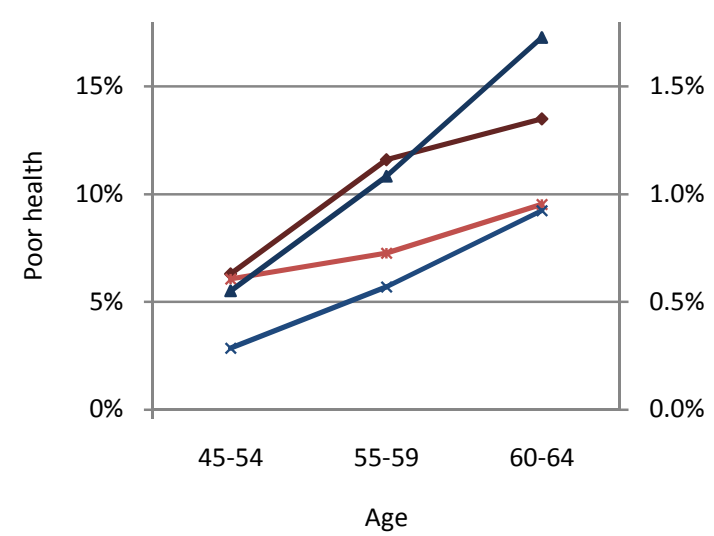

— Poor health $1976 \ldots$ Poor health 2005
B. Women

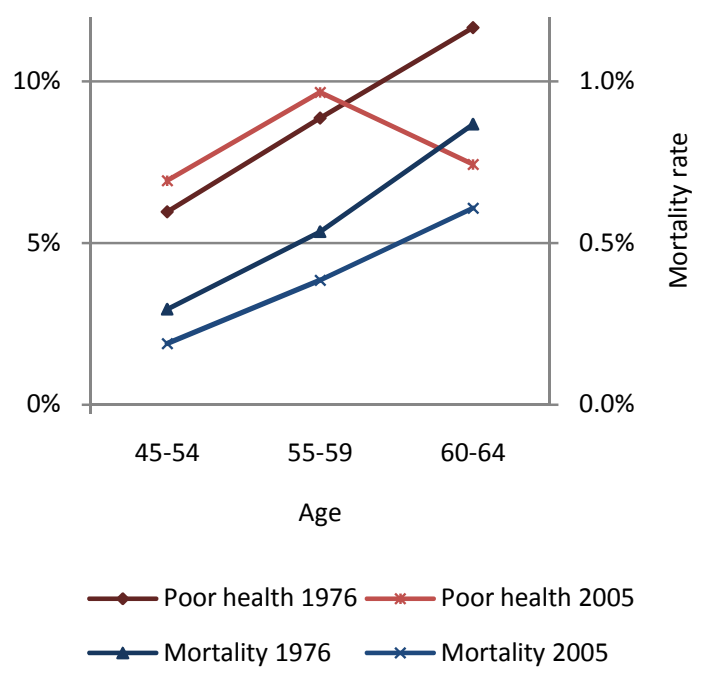

Figure 7. Share of population in poor health and the mortality rate, 1976 and 2005

The two main conclusions are highlighted in Figure 7, which shows the share of individuals with a self-reported poor health and the mortality rate in the three age groups in 1976 and 
2005. Panel A shows that the health of men in the youngest age group, aged 45-54, has hardly improved over the 30 year period, while the health of men in ages 55-59 and 60-64 has improved substantially. For women, the gains in mortality are much smaller than for men over the period, and the share of women with a self-reported poor health has even increased for the younger age groups, aged 45-54 and 55-59. For older women, aged 60-64, on the other hand, the share in poor health has decreased substantially over the period.

\section{Disability insurance utilization and the relation to labor market outcomes}

\subsection{The development of disability insurance recipiency}

Figure 7 shows the prevalence of disability insurance recipiency by the end of the year from 1962 to 2009 for men and women, respectively. ${ }^{4}$ The prevalence is defined as the share of the population in an age group that receives full or partial disability benefits in a given year. Panel A reveals a clear upward trend of disability insurance prevalence for men in all age groups until the early 1990s. The prevalence for men in the oldest age group, aged 60-64, increased from around 10 percent in 1962 to above 35 percent in 1995. The increase from about 5 percent in 1962 to about 18 percent in 1995 for men in the age group 55-59 is also notable. After the mid 1990s, there is a clear trend break for men in the oldest age group, with a decrease in the disability insurance prevalence from above 35 percent to about 20 percent. A smaller decrease can be seen in the age group 55-59. The prevalence of disability insurance recipiency for men aged 45-54, however, continued to increase until the late 2000s.

Panel B shows a similar increase in the prevalence of disability insurance recipiency for women until the early 1990s. The increase was most rapid for women aged 60-64, for whom the prevalence of disability insurance recipiency rose to the same level as that for men. For the two younger age groups, however, DI recipiency increased to even higher levels than for men of the same age. A similar trend break as that for men can be seen also for women in the early 1990s, but the development since then has been far less favorable than that for men. The prevalence of DI recipiency for women in the oldest age group has remained above 30

\footnotetext{
${ }^{4}$ The prevalence of DI recipiency is measured in January from 1963 to 1984 and in December from 1985 onwards. In our analysis, we let the January figures from 1963 to 1984 represent DI recipiency at the end of the previous year. For example, DI recipiency in January 1963 is presented as DI recipiency in 1962.
} 
percent, and the prevalence in the younger age groups continued to rise until the mid or late 2000s. Compared to the early 1960s, the level of DI recipiency has more than tripled for all women.

A. Men

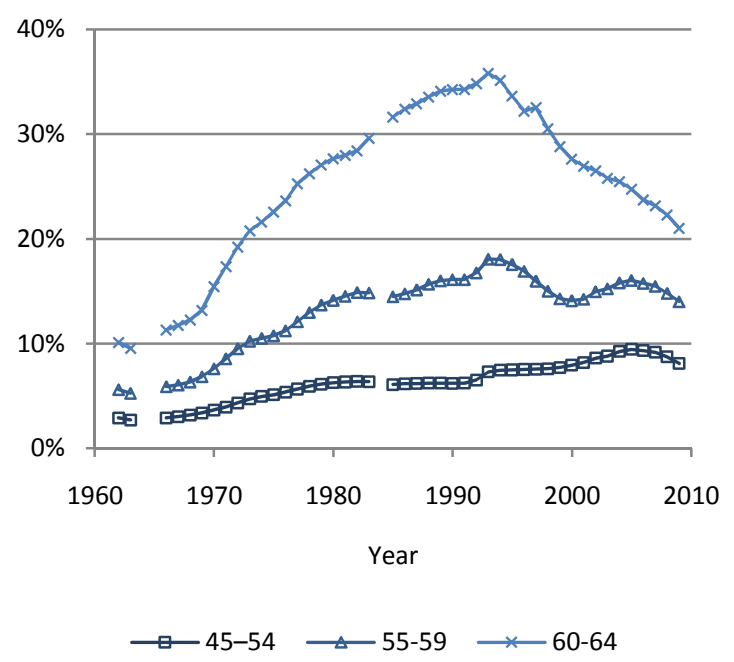

B. Women
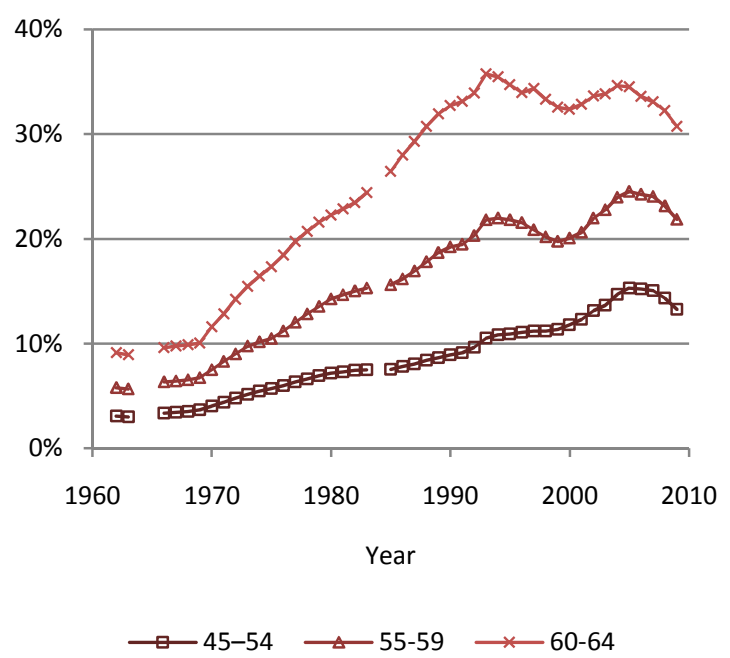

Figure 7. Disability insurance prevalence by gender and age group, 1962-2009

Source: The Swedish Social Insurance Agency

Figure 8 shows the development of the incidence of disability insurance recipiency from 1971 to 2009. The incidence is defined as the share of the population at risk that starts to receive full or partial disability benefits in a given year, whereas the population at risk is defined as all individuals in the age group that are not already receiving disability benefits. Due to limited data availability, we redefined the youngest age group to age 50-54 rather than 45-54 as in the previous section.

Figure 8 shows that the incidence of DI recipiency in the two youngest age groups increased in a similar manner for men and women until the early 1990s. In the oldest age group, however, the development is somewhat different across genders. The incidence for men aged 60-64 started at a historically high level in the beginning of the 1970s and decreased until the early 1980s, while the incidence for women aged 60-64 was relatively stable until the early 1980s. Thereafter, the incidence of DI recipiency in the oldest age group increased for both men and women until the early 1990s, although the level for men was still higher than that for women. From the early 1990s onwards, the incidence of DI recipiency has developed similarly across demographic groups. The incidence decreased markedly in all age groups 
during the 1990s. In the early 2000s, the incidence once more increased, in particular for women, but then declined to historically low levels in all groups until 2009.

A. Men

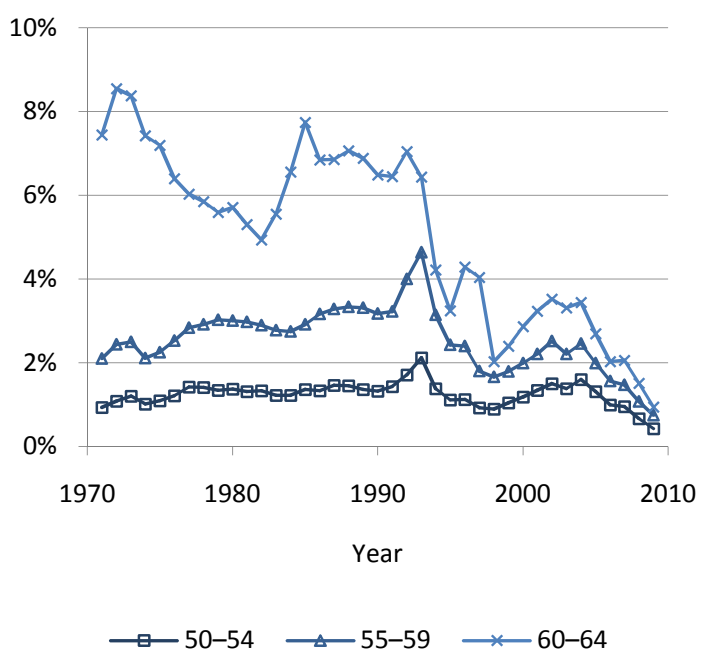

B. Women

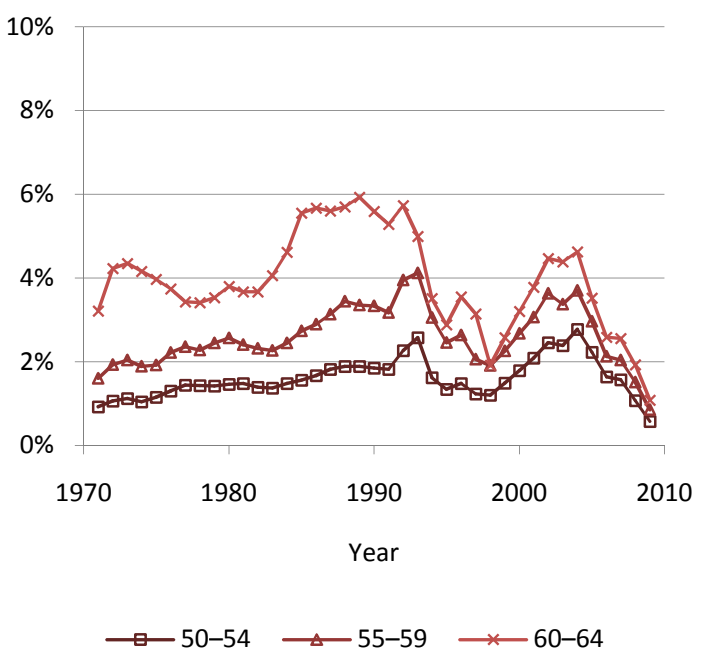

Figure 8. Disability insurance incidence by gender and age group, 1971-2009

Source: The Swedish Social Insurance Agency

The recent decline in the incidence of disability insurance recipiency is remarkably large. Since the upward trend was broken in 2005 , the incidence has steadily declined to very low levels in all age groups. As described in section 2, new regulation came into place in July 2008 introducing stricter eligibility criteria for disability benefits. It is apparent, however, that the decline begun well before then. The decline in incidence can also be seen in the development of the prevalence of disability insurance recipiency in Figure 7, although the levels are still high. If the incidence remains at these low levels, we are likely to see a steep decline in the prevalence of DI recipiency over the coming years.

Figure 9 shows the development of disability insurance incidence by diagnosis. We present the three most common groups of diagnoses for disability benefits award: circulatory diseases, musculoskeletal diseases and mental disorders. We also include a category for all other diagnoses. For the group aged 60-64 we add a category for labor market reasons for the part of the period when this was a sufficient criterion for DI eligibility in this age group, as described in Section 2. 
A. Men age $50-54$

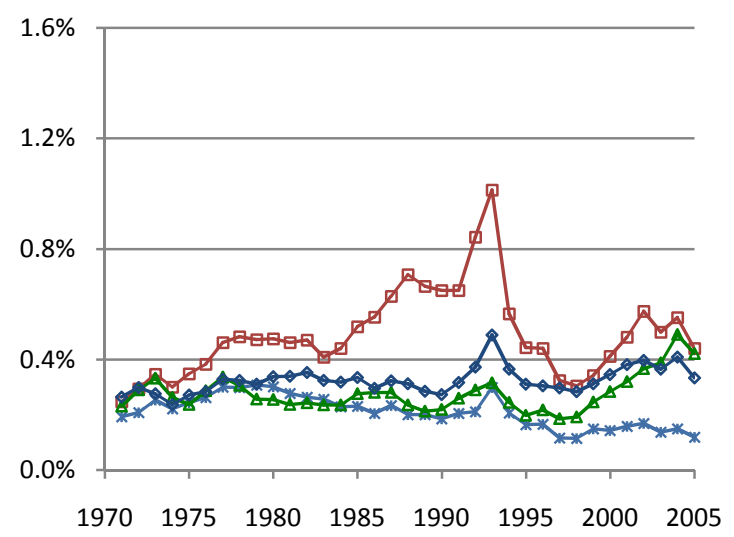

C. Men age 55-59

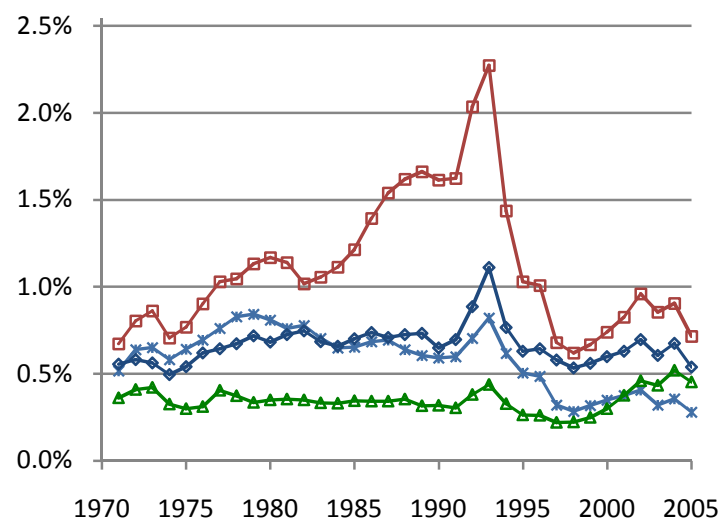

E. Men age 60-64
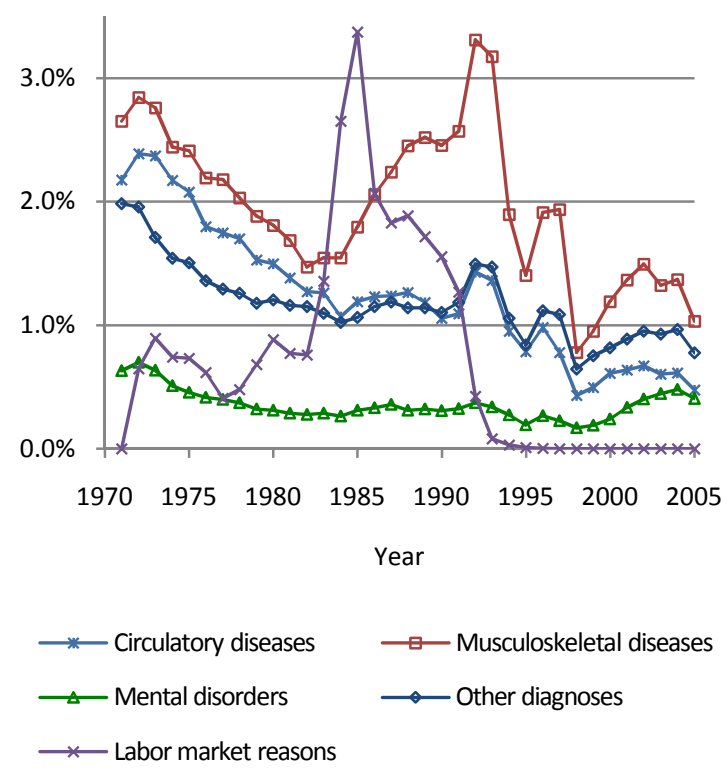

B. Women age $50-54$

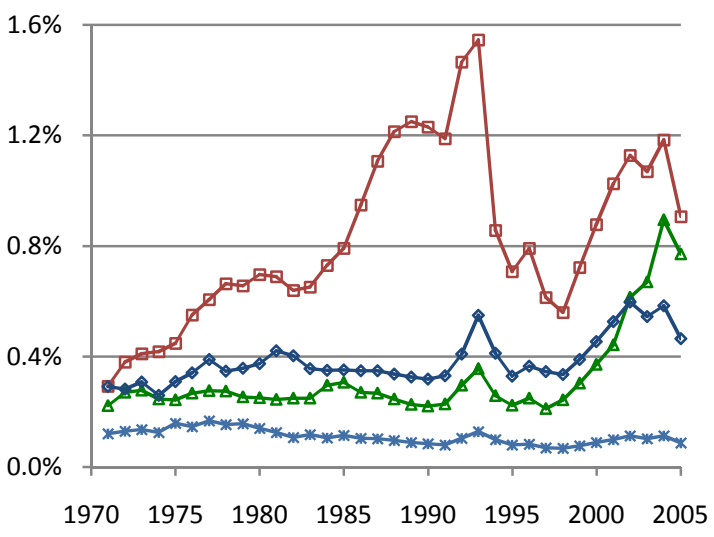

D. Women age 55-59

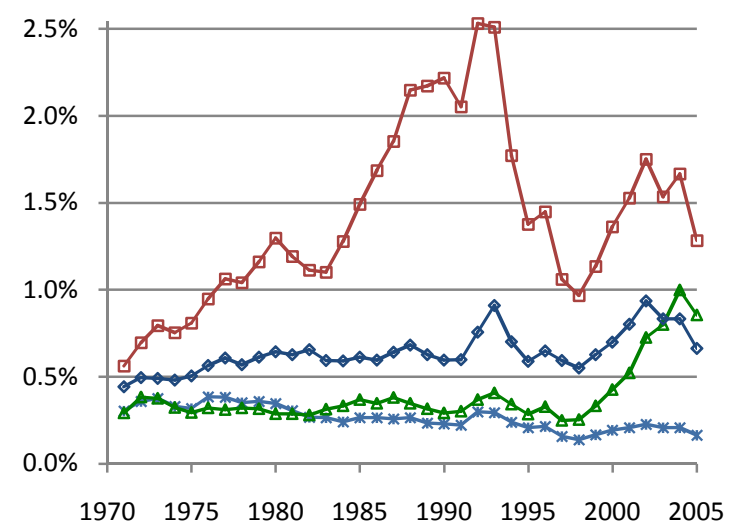

F. Women age 60-64

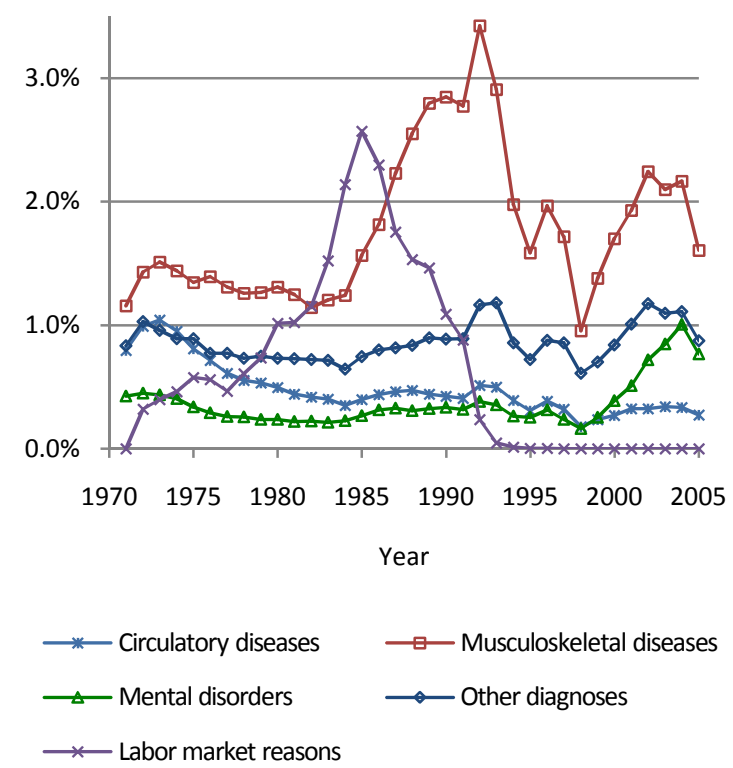

Figure 9. Disability insurance incidence by diagnosis, 1971-2005.

Source: The Swedish Social Insurance Agency 
The figure shows that musculoskeletal diseases have been the most common diagnosis for disability benefits award in all demographic groups throughout the period. The large increases in the incidence of DI recipiency until the early 1990s and the subsequent sharp declines were primarily attributed to musculoskeletal diagnoses. The figure also reveals that mental disorders have become increasingly important in recent years in all demographic groups, in particular for the youngest age group and for women. Circulatory diagnoses have lost importance over time in all demographic groups. Even though musculoskeletal diseases and mental disorders explain a large share of the increase in incidence during the early 2000s, also the series capturing other diagnoses shows a similar increase.

For the oldest age group, the pure labor market reasons, introduced in 1972, did not become important until the 1980s. In the mid 1980s, labor market reasons were the most common reason for granting disability benefits to 60-64 year olds. Thereafter, the importance of labor market reasons declined substantially while the importance of musculoskeletal diagnoses increased.

\subsection{The development of labor market outcomes}

To describe the development of some central labor market outcomes we use data from the Labor Force Surveys, collected by Statistics Sweden. We present the development from 1963 to 2007 for men and women in the age groups 45-54, 55-59 and 60-64. Figure 10 shows the development of the employment rate. Panel A reveals a similar pattern across age groups for the development of male employment over time. Male employment decreased from the early 1960s until the early 1990s, and then experienced a pronounced dip during the recession in Sweden in the early 1990s. From the late 1990s onwards, male employment again increased. The pattern is most pronounced for the age group 60-64, where the employment rate decreased from above 80 percent in 1963 to around 50 percent in the mid 1990s, and then increased to about 65 percent in 2009. Changes in employment in the age group 45-54 are much smaller. Employment in this age group remained above 90 percent until the economic crisis in the early 1990s, and then shifted down to a level just below 90 percent.

Panel B in Figure 10 shows a different development of the female employment rate. Until the 1990s, employment increased substantially for women in all age groups. The increase was most rapid for the two youngest age groups, where employment increased from 55 to 90 
percent in the age group $45-54$ and from 40 to 80 percent in the age group 55-59. By the time of the economic crisis in the beginning of the 1990s, the stable increase in employment ceased and was followed by a slight decrease in all age groups. In recent years, however, there has been a marked increase in the employment rate of women aged 60-64. Between 2000 and 2007, employment increased by 15 percentage points to about 58 percent in this group. Also the female employment rate in the age groups 45-54 and 55-59 has increased since the late 1990s.

\section{A. Men}

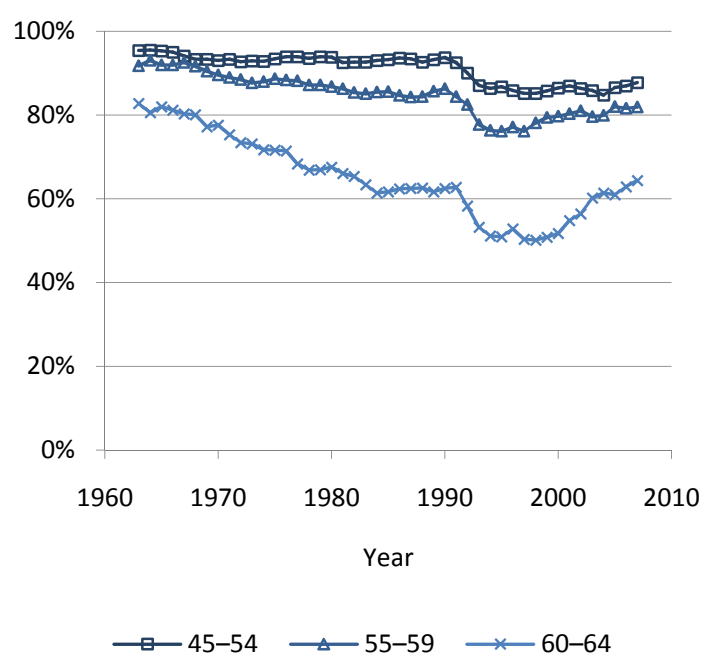

B. Women

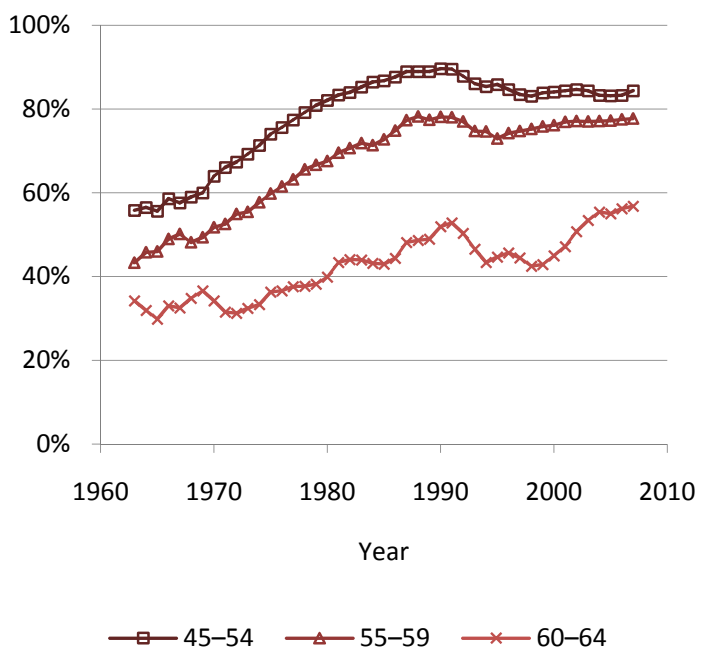

Figure 10. Employment rates by gender and age group, 1963-2007 Source: Swedish Labor Force Survey, Statistics Sweden

A. Men

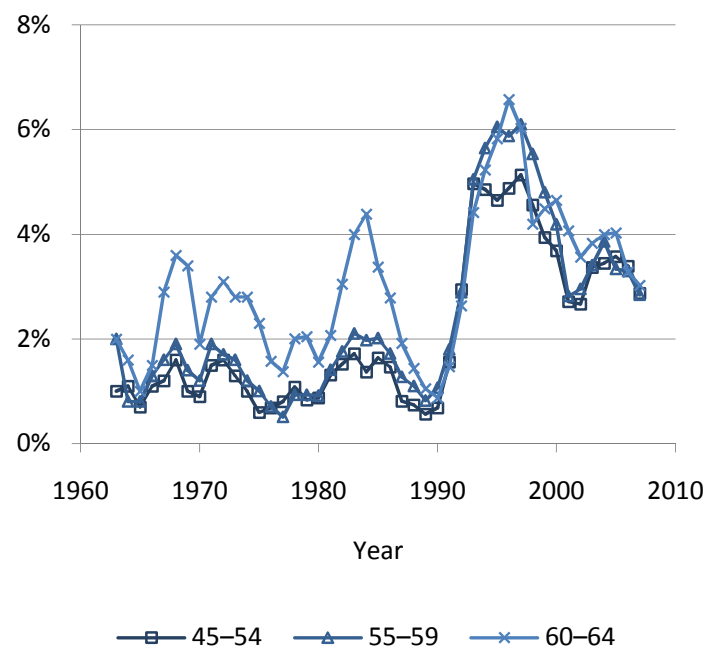

B. Women

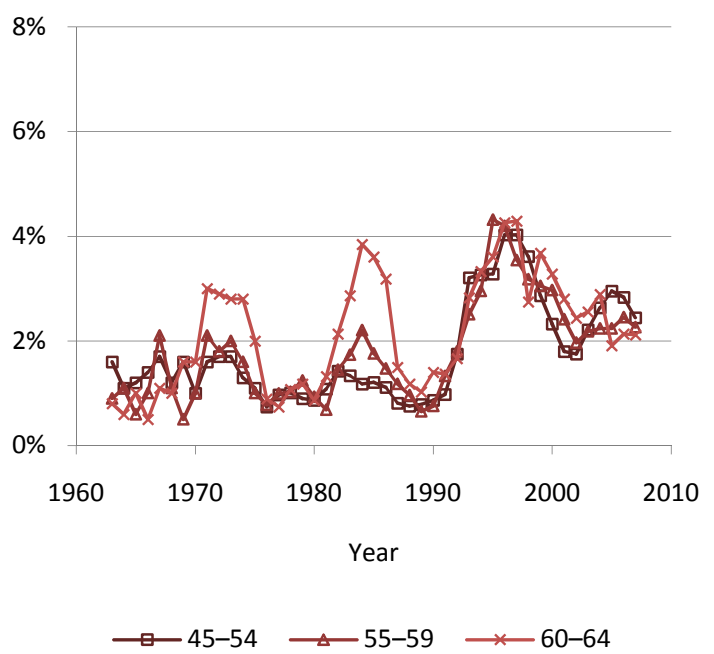

Figure 11. Unemployment rates by gender and age group, 1963-2007 Source: Swedish Labor Force Survey, Statistics Sweden 
Figure 11 shows the development of the unemployment rate. As opposed to the employment rate, the unemployment rate has developed in a similar manner for men and women. There are two notable properties of the development. First, unemployment in the oldest age group seems to have been more sensitive to business cycle movements than other age groups before 1990 . After 1990, the series for different age groups correspond remarkably well. Second, the unemployment rate seems to have increased to a permanently higher level in all age groups after the recession in the beginning of the 1990s.

Figure 12 shows the share of the population not participating in the labor force. Panel A reveals an increasing trend in the share of the male population out of the labor force in all age groups. The steepest increase occured for the oldest age group, aged 60-64, from about 15 percent in 1963 to about 45 percent in 2000. Thereafter, however, the trend reversed and nonlabor force participation for men aged 60-64 decreased to a level just above 30 percent in 2009. The increase in non-labor force participation in the two younger age groups has been much more modest and the series have stabilized rather than declined in the 2000s.

A. Men

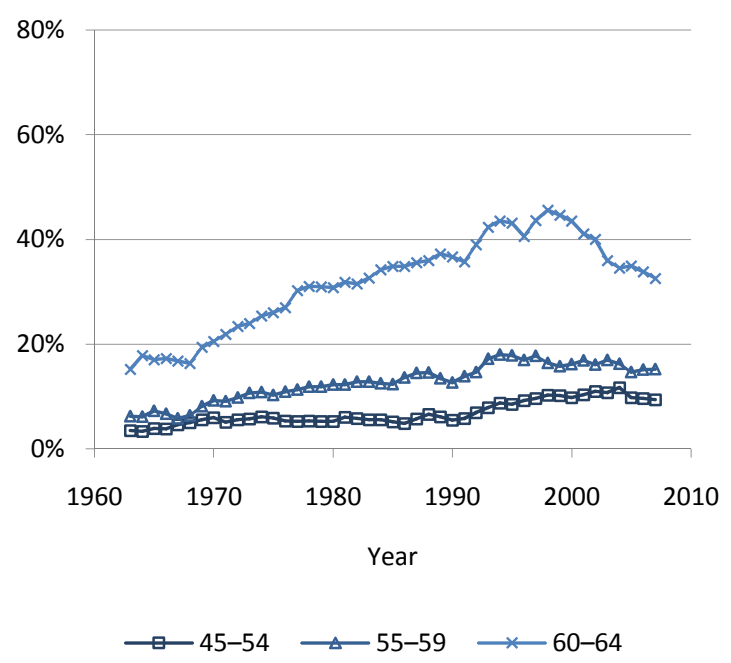

B. Women

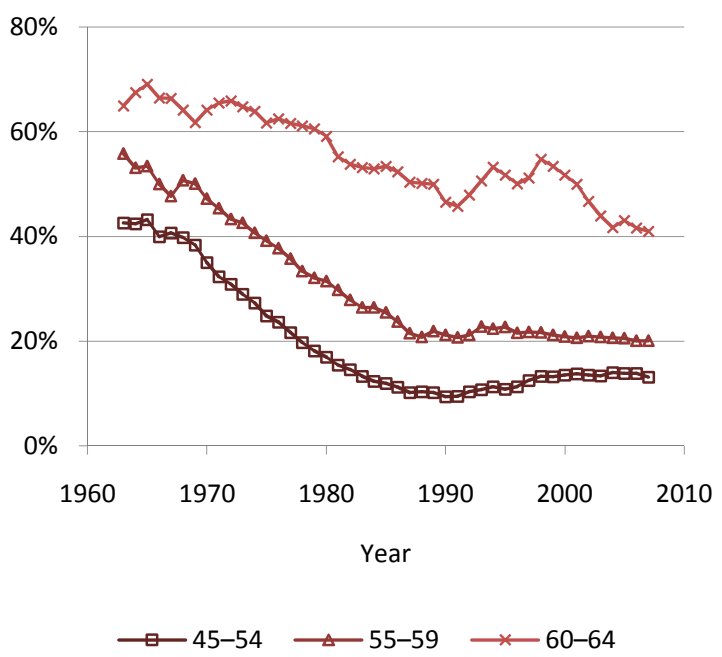

Figure 12. Non-labor force participation rates by gender and age group, 1963-2007 Source: Swedish Labor Force Survey, Statistics Sweden

Panel B in Figure 12 reveals a very different development of the non-labor force participation rate for women compared to men. There has been a decreasing trend in all age groups and the decrease has been most pronounced in the two younger groups. Non-labor force participation decreased from 45 to 10 percent for the age group $45-54$ and from 55 to 20 percent for the 
age group 55-59 between 1963 and 1990. Thereafter, the level has remained stable for the age group 55-59 and increased slightly for the age group 45-54. The non-labor force participation rate for the oldest age group, aged 60-64, decreased less rapidly, from 65 to 40 percent over the full period.

Figure 13 shows the labor force participation rate in one-year age groups in 1965, 1985 and 2003 for men and women, respectively. Panel A reveals a marked decrease in the labor force participation of men above the age of 58 between 1965 and 1985, but no visible change between 1985 and 2003. In the ages below 58, however, there was a small but visible decrease in the labor force participation both between 1965 and 1985 and between 1985 and 2003. Panel B reveals a large increase in female labor force participation at ages below 65 between 1965 and 1985, and a smaller increase between 1985 and 2003. Beyond the age of 65, there was a decrease in labor force participation between 1965 and 1985 that can be explained by a decrease in the normal retirement age from 67 to 65 in 1976.
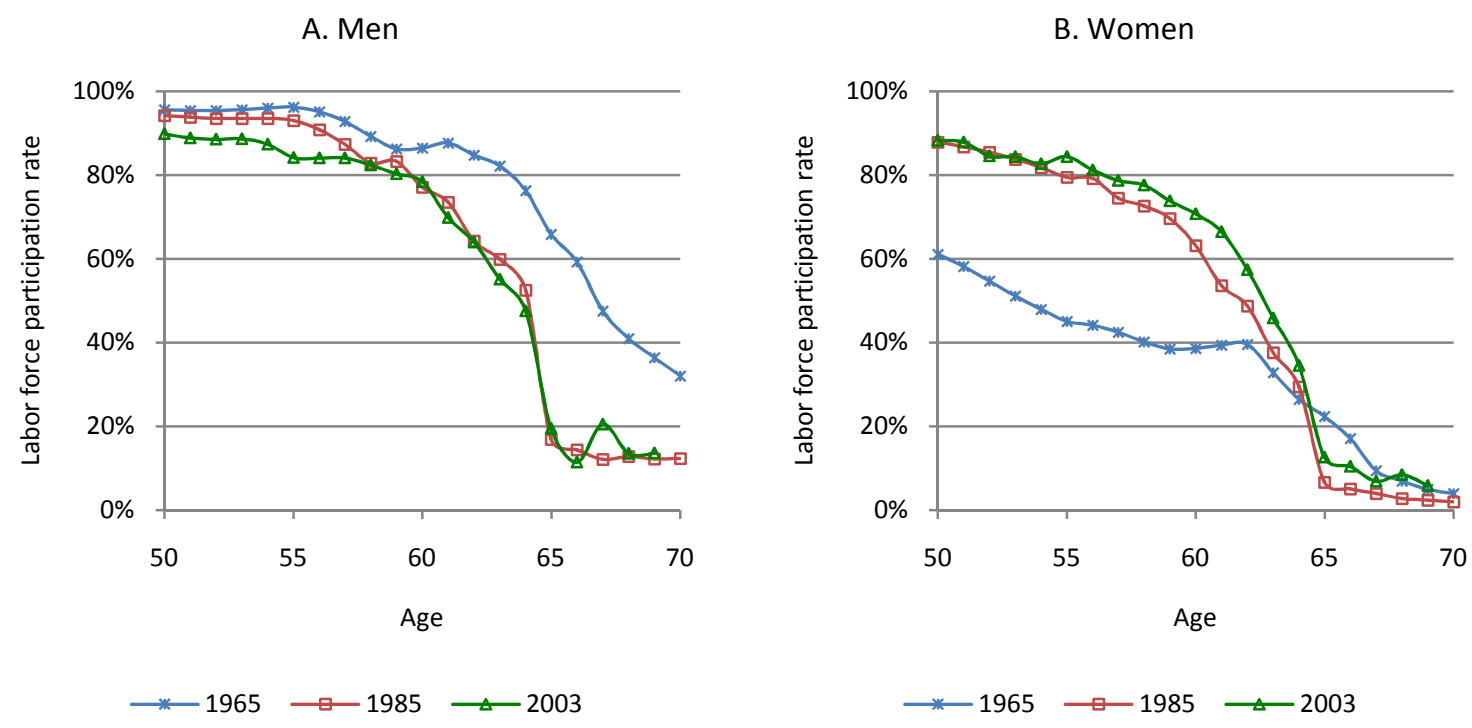

Figure 13. Labor force participation by age and year Source: Own calculations based on data from Statistics Sweden

In section 3 we showed that the mortality rate has fallen quite dramatically in all age groups in recent decades. An increased life expectancy can affect the time an individual spend in the labor force, the time an individual spends as a retiree, or both. To report the changes in labor force participation over time without correcting for changes in mortality, as we have done so far, implicitly implies that all gains in life expectancy are taken out in time as a retiree. The 
other extreme would be that the time as a retiree is held constant and the increased life expectancy only affects the time spent in the labor force. One way of investigating this alternative is to calculate labor force participation rates at constant mortality risks.

The results from this exercise are shown in Figure 14, which shows the labor force participation rate at a given mortality rate. As was apparent in Figure 13, labor force participation for men decreased even when not taking the decrease in mortality into account. Figure 14 hence reveals an even larger decrease in labor force participation rates for men. In contrast to the results in Figure 13, however, there is also a large decrease between 1985 and 2003, a period during which the mortality rate of men decreased significantly. Interestingly, the increased labor force participation for females between 1965 and 1985 that was shown in Figure 13 reverses in Figure 14, since mortality improves more than labor force participation increases. Only for very low mortality rates labor force participation still increased between 1965 and 1985. For women at higher mortality rates, labor force participation decreased substantially between 1965 and 1985, and continued to decrease until 2003.

A. Men

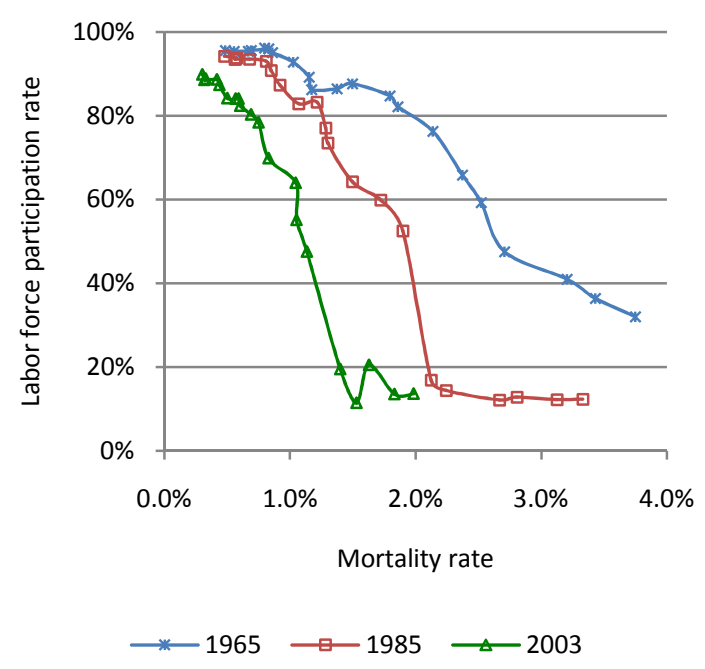

B. Women

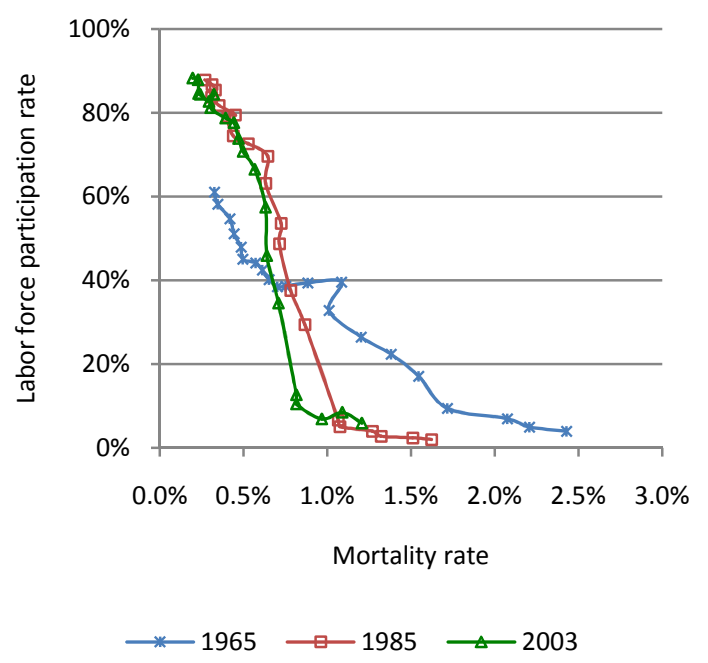

Figure 14. Labor force participation by mortality rate and year

Source: Own calculations based on data from Statistics Sweden

\subsection{Pathways to retirement}

Figure 15 shows the development of the share of the population receiving disability benefits, the share of non-employed and the share not participating in the labor force from 1963 to 
2009. Panel $\mathrm{C}$ and $\mathrm{E}$ show a large increase in non-employment and non-labor force participation of elderly men between 1970 and 1988, along with a corresponding increase in disability insurance recipiency. In the age group 55-59, non-employment increased by 5.2 percent between 1970 and 1988, non-labor force participation by 5.3 percent and disability insurance recipiency by 8.1 percent. For men aged 60-64 the corresponding figures were 15.0, 15.5 and 15.2. The disability insurance hence seems to have been the dominating pathway to retirement for older males until 1990.

For men aged 45-54, the same close correspondence between non-employment and non-labor force participation on the one hand and disability insurance recipiency on the other is not apparent. Non-employment and non-labor force participation increased in the end of the 1960s and did not increase again until 1990, while disability insurance recipiency was gradually increasing.

The right-hand panels in Figure 15 show a very different pattern for females until 1990. The large gap between disability insurance recipiency and the non-labor force participation rate consists of the diminishing fraction of homemakers. The fact that the gap closes earlier for younger age groups tells us that this development is primarily a cohort effect. Since the close link between non-employment, non-labor force participation and disability insurance recipiency for men was broken in 1990, the development for women has been more similar to that for men. In all age and gender groups, a gap emerged between disability insurance recipiency and non-employment from 1990 onwards. In the oldest age group, this gap primarily consisted of increased non-labor force participation that was not due to increased disability insurance recipiency.

To study the background to this development, we use the annual income statistics from tax returns. Figure 16 shows the share of men and women aged 55-59 and 60-64 with one of the four main income security programs in Sweden as the main income source. These include the disability insurance, the sickness insurance, the unemployment insurance and occupational insurance. An individual is classified as receiving his or her main income from a certain program if the benefits from the program account for 50 percent or more of the total yearly income. 

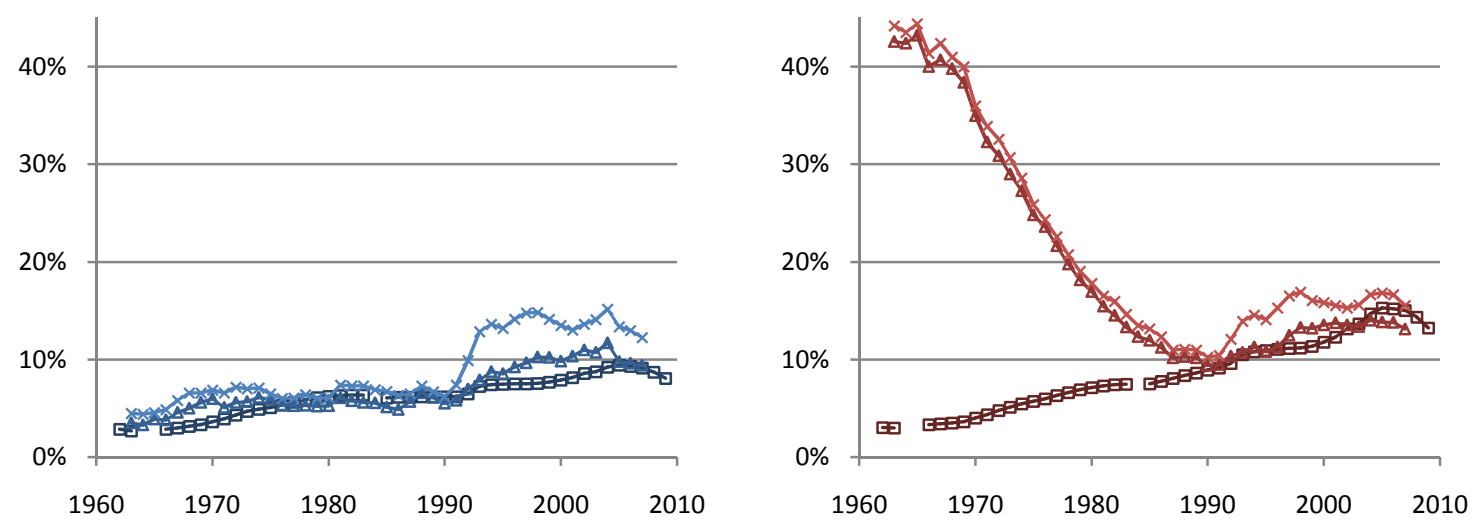

C. Men age 55-59

D. Women age 55-59
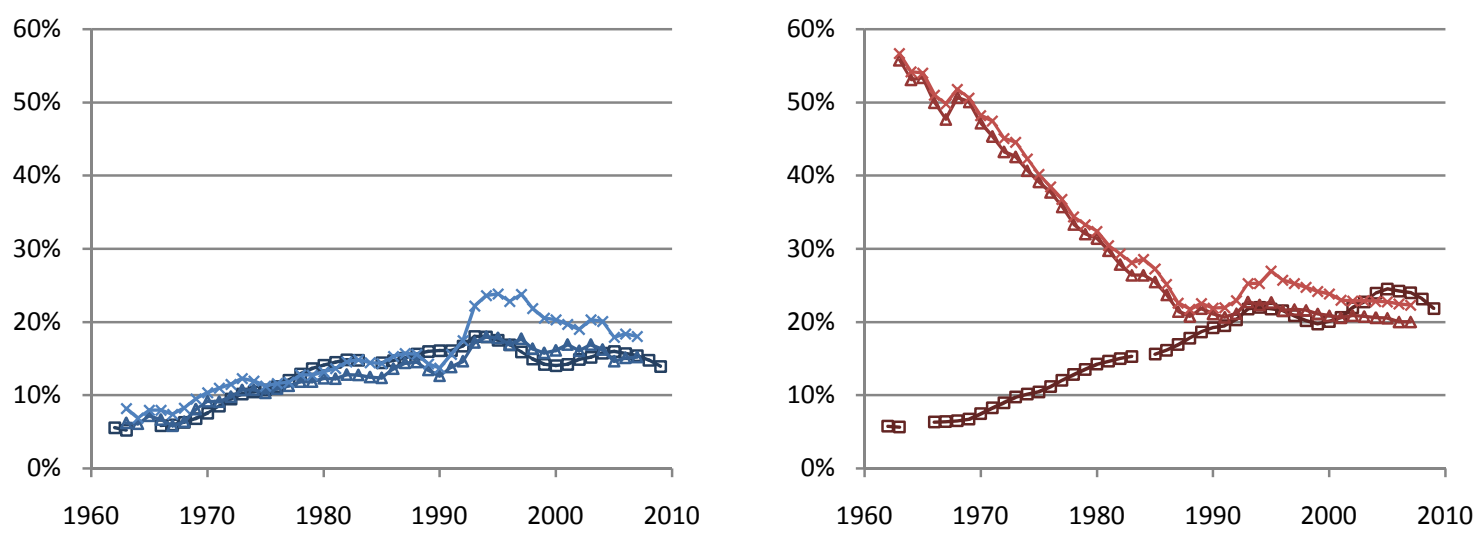

E. Men age 60-64

F. Women age 60-64
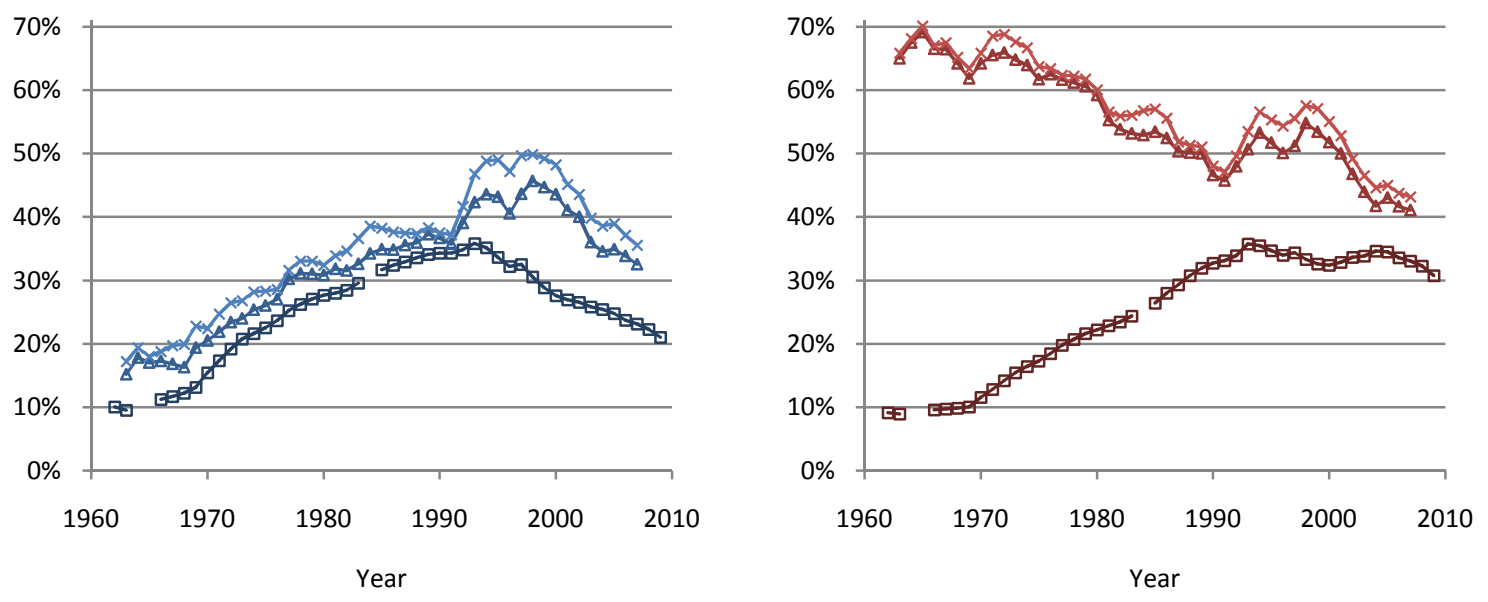

$\longrightarrow$ DI prevalence

$\longrightarrow$ DI prevalence

$\triangle$ Non-labor force participation rate

$\triangle$ Non-labor force participation rate

$\longrightarrow$ Non-employment rate

Figure 15. DI prevalence, non-labor force participation and non-employment

Source: The Swedish Social Insurance Agency and Statistics Sweden 
The upper panels in Figure 16 show that the gap between disability insurance recipiency and non-employment in the age group 55-59 has been mainly accounted for by the unemployment insurance. Also the sickness insurance has been a main income source for a substantial share of the population in this age group, and the relative importance of the sickness and the unemployment insurance has shifted over time. The lower panels in Figure 16 show a different pattern for the age group 60-64. A large share of the gap between disability insurance recipiency and non-labor force participation in this age group after 1990 has been accounted for by benefits from occupational insurance schemes.

A. Men age 55-59

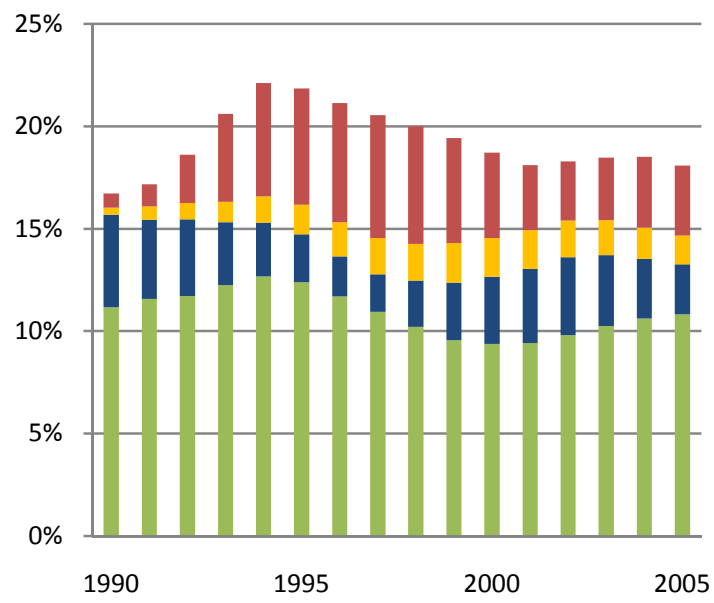

C. Men age 60-64

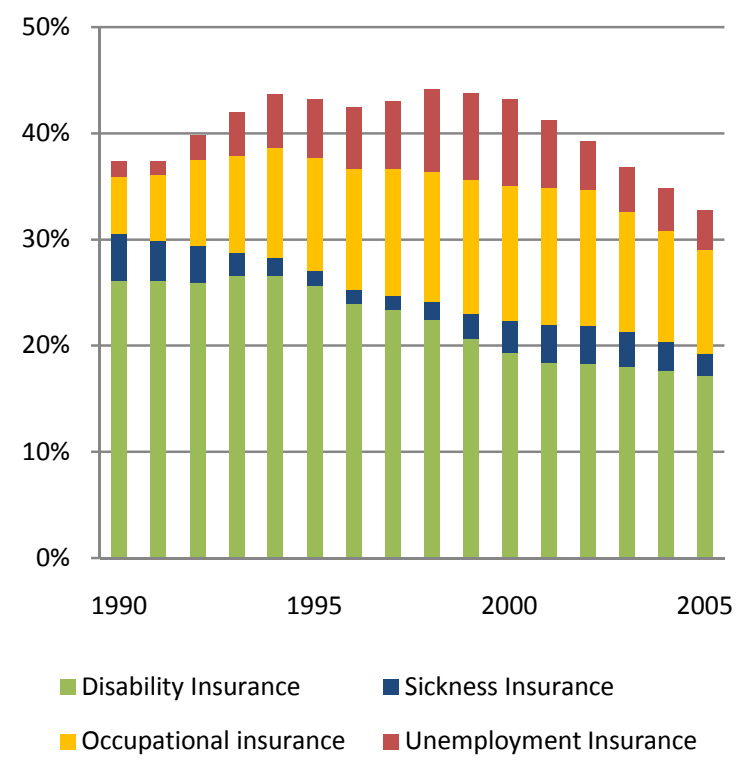

B. Women age 55-59

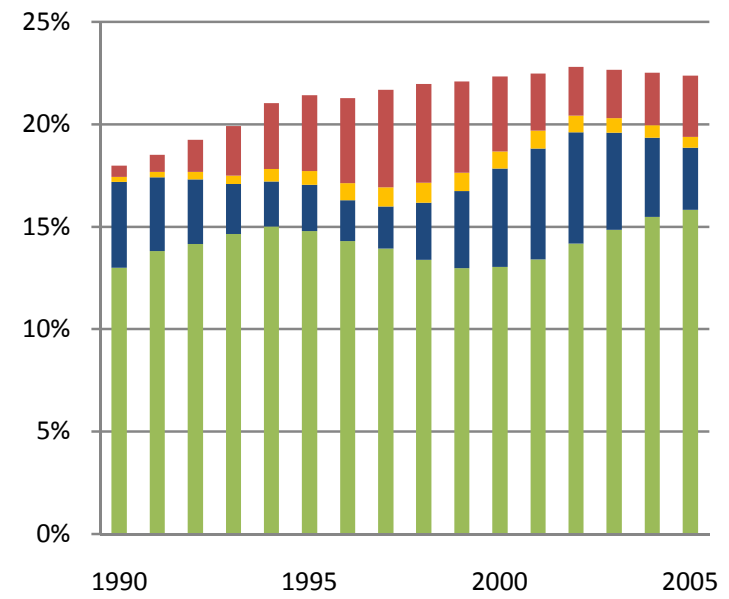

D. Women age $60-64$

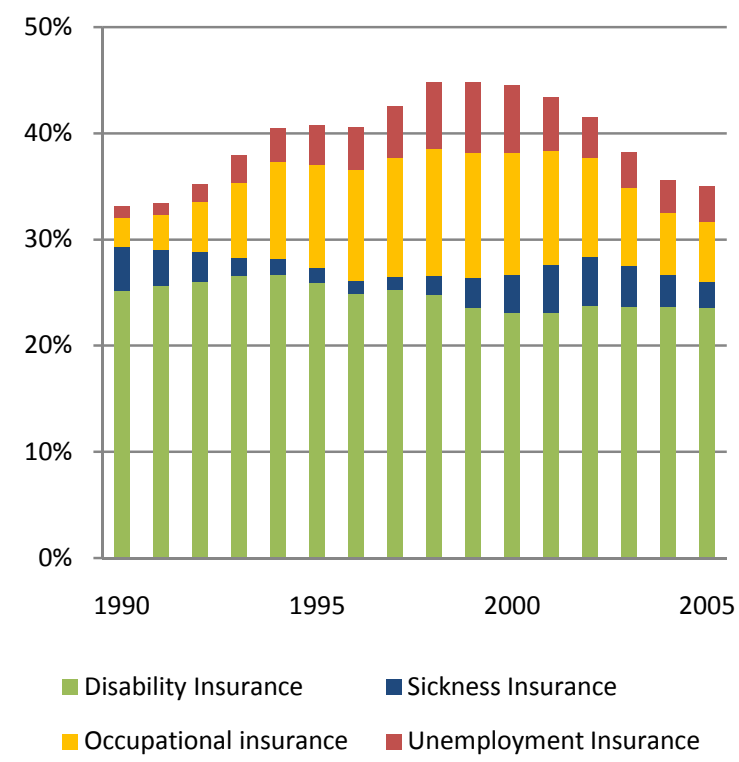

Figure 16. Main income source, 1990-2005

Source: Annual income statistics, Statistics Sweden 


\subsection{Conclusions about the disability insurance and labor market outcomes}

The results in this section showed some general patterns. The development of disability insurance recipiency and labor market outcomes can be divided into two main eras; before and after 1990. From the early 1960s until 1990, the share of disability insurance recipients increased in all demographic groups. For males, the increase was closely accompanied by an equal increase in non-labor force participation and non-employment. For females, the correspondence between disability insurance recipiency and labor market outcomes was weak, but the gap was closing over time as female labor force participation increased.

After 1990, the development of disability insurance recipiency was different across demographic groups. While disability insurance recipiency decreased for men aged 55-59 and 60-64, it continued to increase for men and women aged 45-54 and women aged 55-59, and only stabilized for women aged 60-64. From the early 1990s, a gap emerged between disability insurance recipiency and non-employment. A closer study showed that the disability insurance program were losing importance as a pathway to permanent exit from the labor force. In the age group 55-59, the unemployment and sickness insurance programs became more important while in the age group 60-64, the role of occupational insurances increased substantially after 1990 .

Finally, we should note the sharp decrease in the incidence of disability insurance utilization in recent years. The incidence reached a historically low level of below 1 percent of the risk population in all demographic groups in 2009. If these exceptionally low levels of incidence continue, it will lead to a sharp decrease in the prevalence of disability insurance utilization in the coming years.

\section{Population health and disability insurance}

\subsection{Disability insurance prevalence and population health}

Figure 17 presents the development of the prevalence of disability insurance recipiency along with the mortality rate and the share of the population with a self-reported impaired work capacity, the share of the population with an impaired ability to move and the share of the 
population with a self-assessed poor health from the Survey on Living Conditions. The most apparent result from this figure is the lack of correlation between the mortality rate and the prevalence of DI recipiency in all of the demographic groups. The increase in the prevalence of DI recipiency for all groups until the mid 1990s instead coincided with decreasing mortality rates.

Turning to the self-reported health indicators in Figure 17, there is a resemblance between the development of impaired work capacity and disability insurance prevalence. The two series shared a similar pattern from the mid 1980s onwards for the two younger age groups, and from the early 1990s onwards for the oldest age group. Both the prevalence of DI recipiency and the share of the population with an impaired work capacity increased more rapidly for women than for men in the two youngest age groups. In addition, the sharp drop in DI recipency among men aged 60-64 since the mid 1990s has coincided with a decrease in the share of the population with an impaired work capacity. The same correspondence is not present between the development of the share of the population in poor health and disability insurance recipiency or the share of the population with an impaired ability to move and disability insurance recipiency.

Figure 18 presents the development of disability insurance prevalence along with three additional health indicators: the share of the population who visited a doctor during the last three months, the share of the population with a long-term disease and the share of the population with a self-assessed good health. From the development of these indicators it is not possible to reject that disability insurance recipiency and population health are unrelated. The indicators did, however, develop more adversely for women and for younger age groups, which was also the case for disability insurance recipiency. 

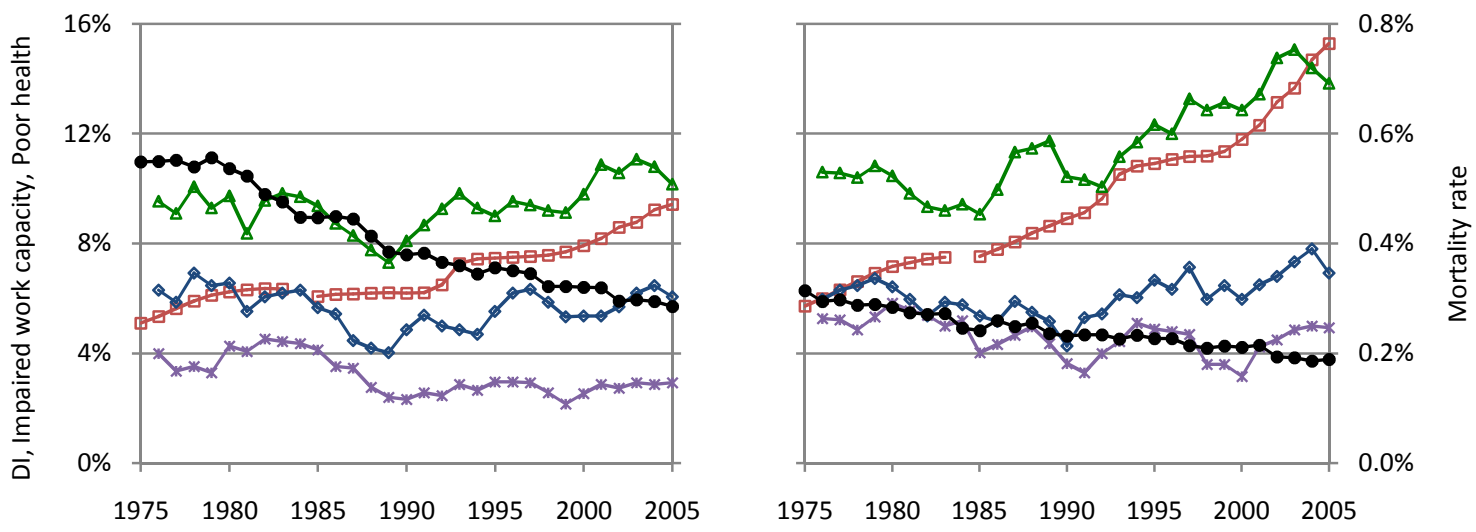

C. Men age 55-59

D. Women age 55-59
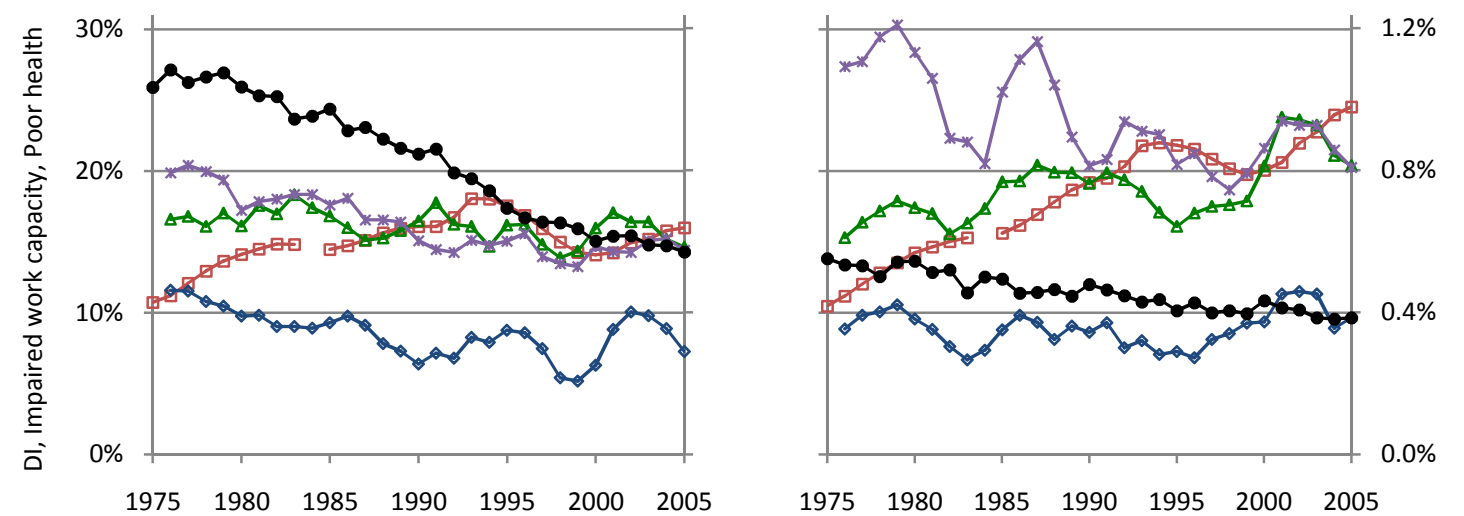

E. Men age 60-64

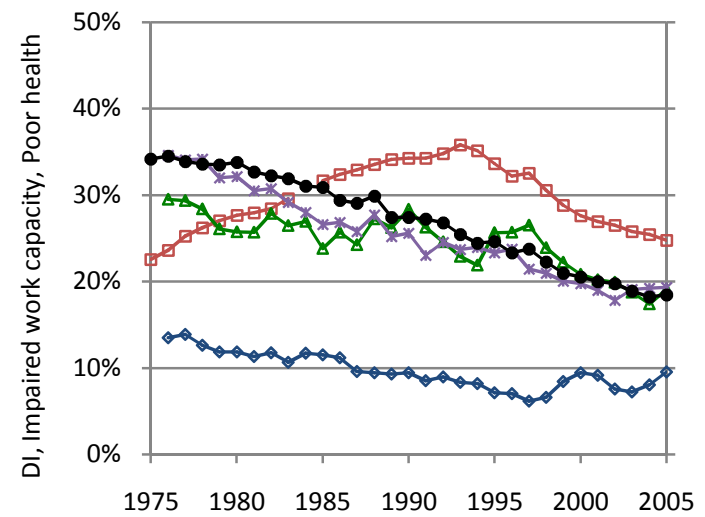

F. Women age 60-64
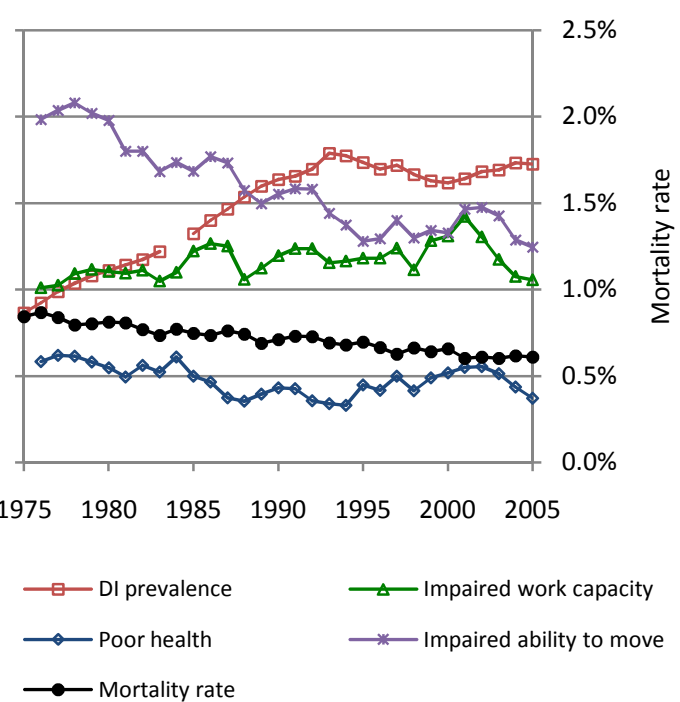

Figure 17. Disability insurance prevalence, mortality and health indicators Source: Statistics Sweden, Swedish Social Insurance Agency 
A. Men age $45-54$

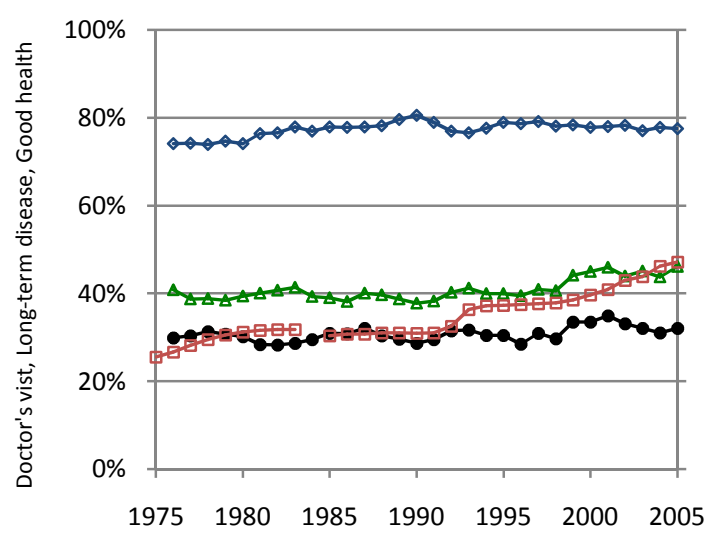

C. Men age 55-59

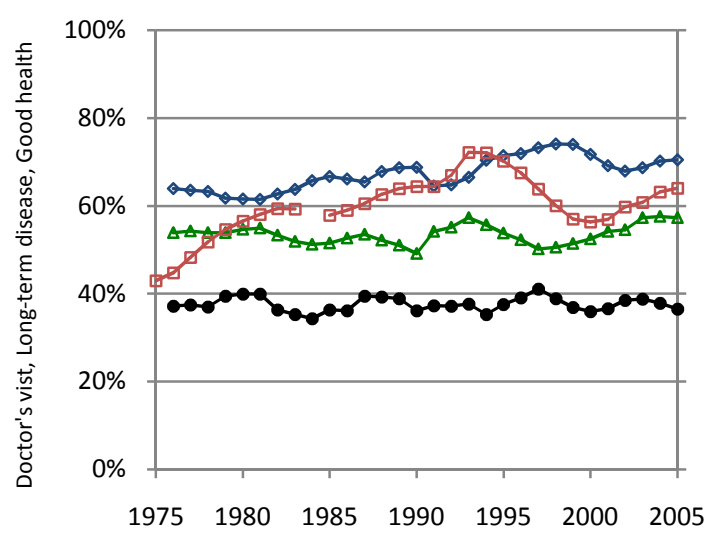

E. Men age 60-64

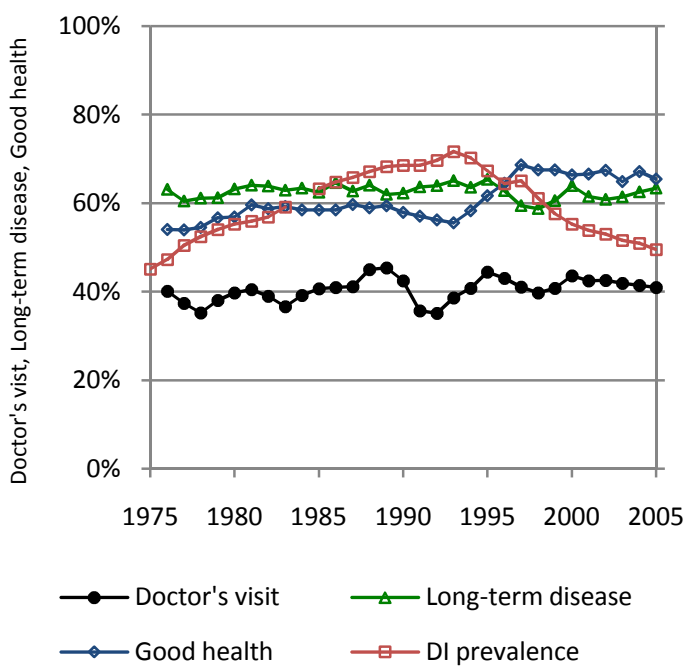

B. Women age $45-54$

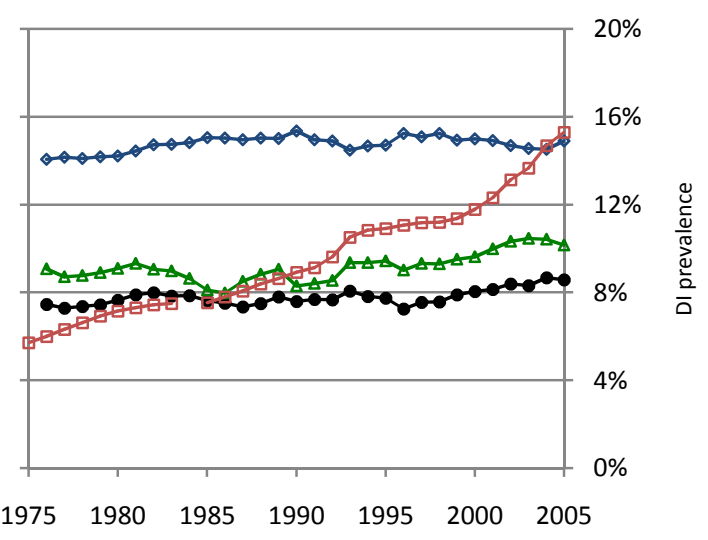

D. Women age 55-59

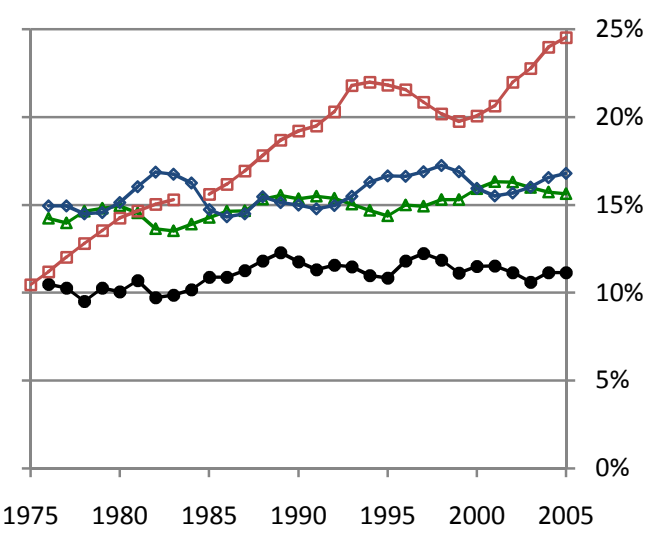

F. Women age 60-64

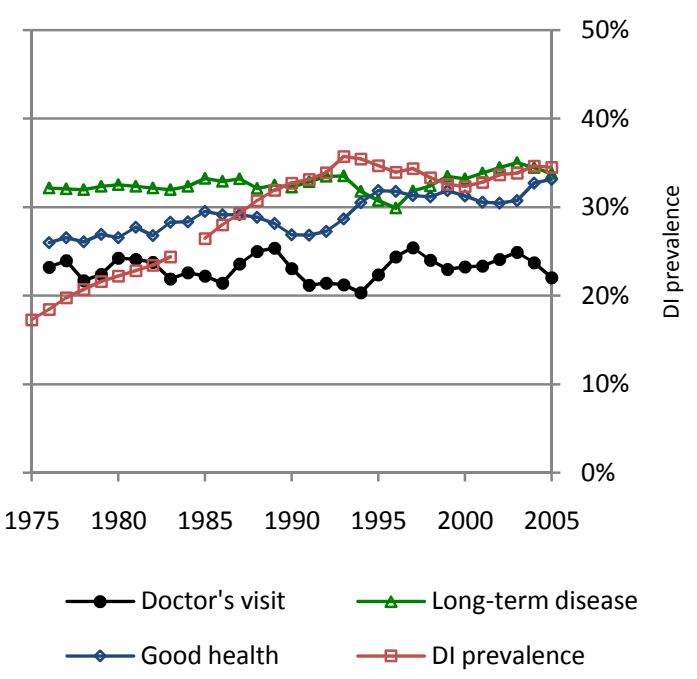

Figure 18. Disability insurance prevalence, mortality and health indicators Source: Statistics Sweden, Swedish Social Insurance Agency 


\subsection{Disability insurance incidence and population health}

To further explore the relation between population health and disability insurance recipiency, Figure 19 through 21 show the development of three diagnosis-specific health measures: (i) the share of the population receiving inpatient care for a specific diagnosis, (ii) the corresponding self-reported prevalence of a specific disease from the Survey on Living Conditions (ULF) and (iii) the diagnosis-specific mortality rate; along with diagnosis-specific incidence of DI recipiency. The figures present this information for the three most common diagnoses for DI eligibility: circulatory diseases, musculoskeletal diseases and mental disorders. We show the development from 1971 to 2005 for men and women in the age groups 55-59 and 60-64.

Figure 19 shows the development for circulatory diagnoses. There has been a decreasing importance of circulatory diagnoses as a ground for disability insurance recipiency in all demographic groups over time. This decrease has been shared with the diagnosis-specific mortality rate. Mortality decreased later for men than for women, and for the younger age group, aged 55-59, the decrease in DI incidence showed a similar pattern. For the older age group, however, the decrease in DI incidence occurred simultaneously across demographic groups, although mortality decreased later for men.

The decreasing trend is not as apparent for the utilization of inpatient care or the self-reported prevalence of circulatory diagnoses. For the older age group, aged 60-64, the development of the utilization of inpatient care showed no resemblance with the development of DI incidence. For the younger age group, aged 55-59, however, there was a similarity between the utilization of inpatient care and DI incidence from the mid 1980s onwards. For men, the development of the self-reported prevalence of circulatory diseases showed no correspondence with DI incidence. For women, however, there was a resemblance between the two series.

Figure 20 shows the development for musculoskeletal diagnoses. There was a clear peak in the importance of musculoskeletal diagnoses for DI incidence from the mid 1980s until the mid 1990s in all demographic groups. Interestingly, this peak is also visible in the selfreported prevalence of musculoskeletal diseases. A smaller upturn in DI incidence can be seen in the early 2000s. Also this pattern is visible in the self-reported disease prevalence, except 
for men aged 60-64. The development of inpatient care utilization due to musculoskeletal diagnoses has been relatively stable over time, although a slight increase is visible as DI incidence increase in the late 1980s. The mortality rate in musculoskeletal diagnoses has been highly volatile but has followed a decreasing trend that did not correspond to the development of the diagnosis-specific DI incidence.

A. Men age 55-59

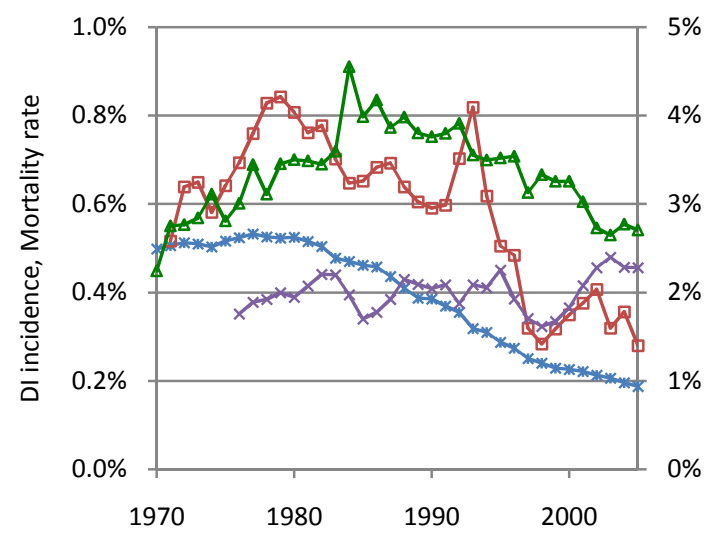

C. Men age $60-64$

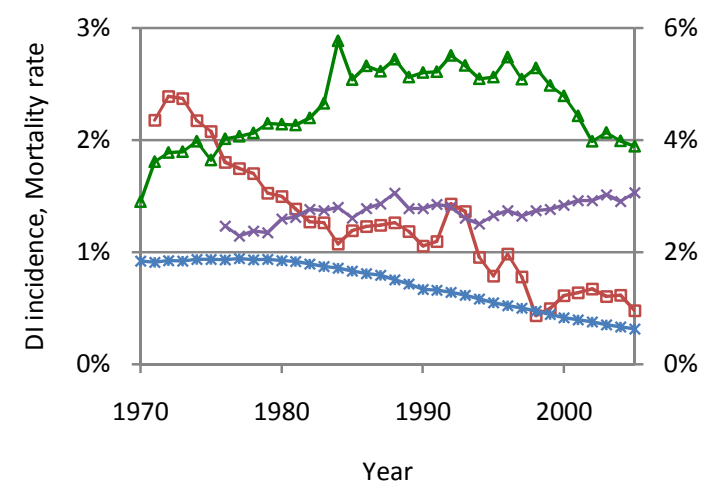

Year

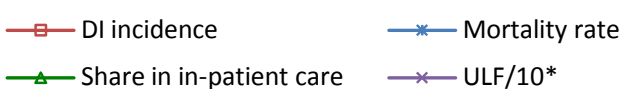

B. Women age 55-59

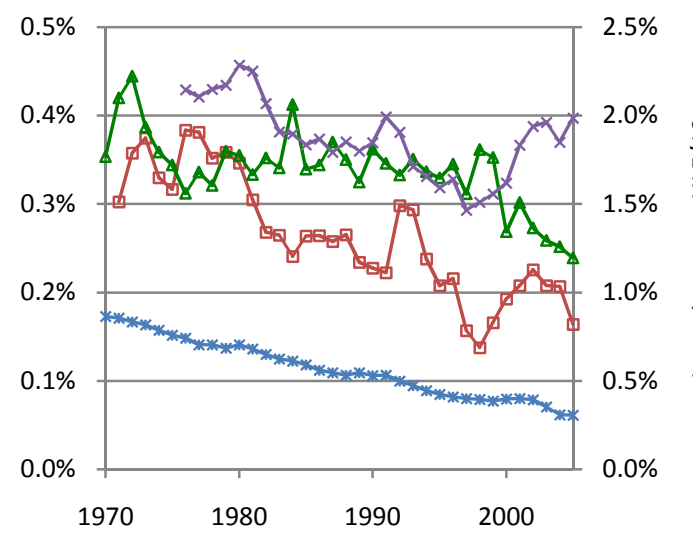

D. Women age 60-64

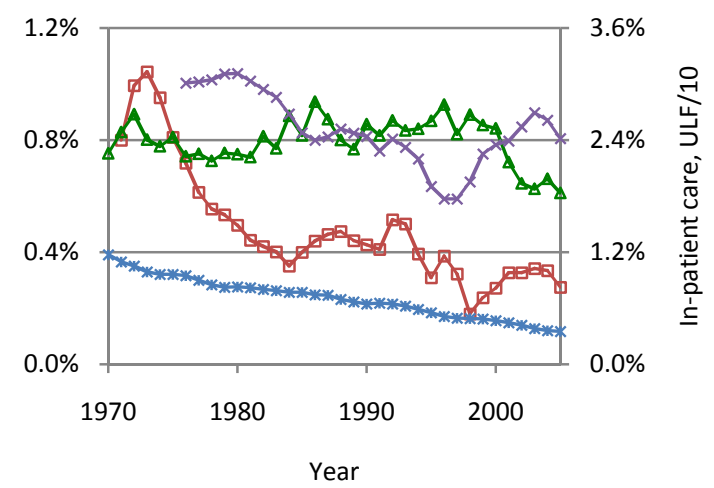

$\longrightarrow$ DI incidence

—- Mortality rate

$\triangle$ Share in in-patient care

$\simeq \mathrm{ULF} / 10^{*}$

$* \mathrm{ULF} / 10=$ Share of the population reporting the particular disease in The Survey on Living Conditions (ULF), divided by ten

Figure 19. Circulatory diagnoses by gender and age group, 1971-2005 
A. Men age 55-59

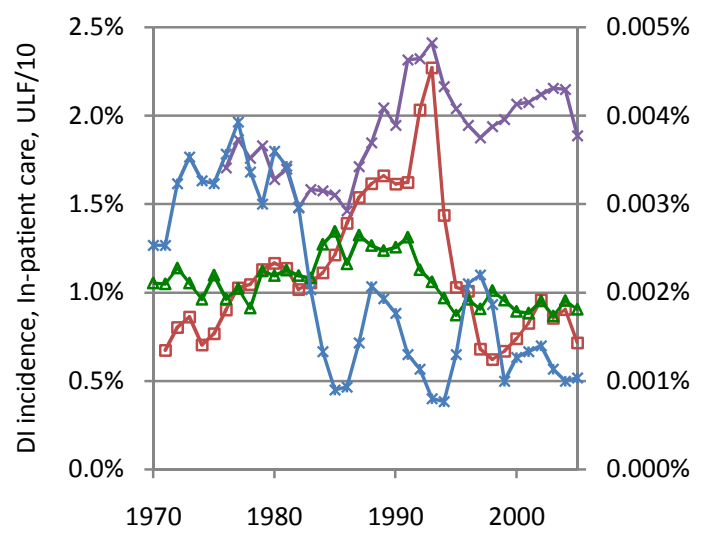

C. Men age $60-64$

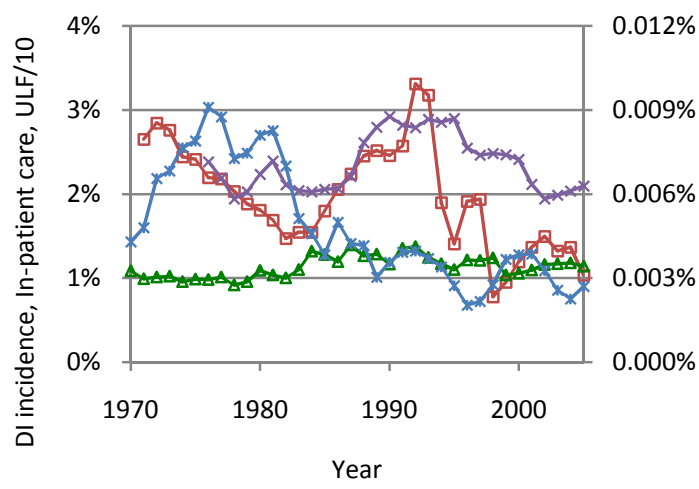

$\longrightarrow$ DI incidence

$\smile$ Share in in-patient care

$\simeq \mathrm{ULF} / 10^{*}$

—-Mortality rate
B. Women age 55-59

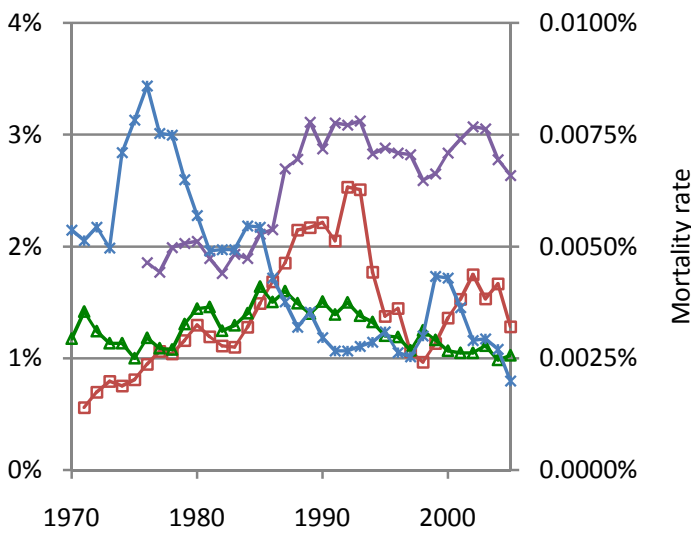

D. Women age 60-64
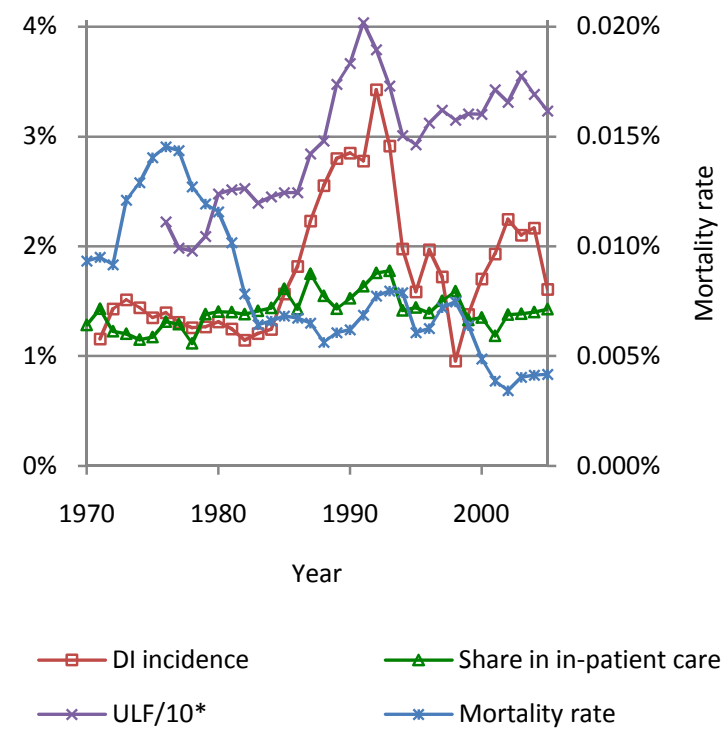

* ULF/10 = Share of the population reporting the particular disease in The Survey on Living Conditions (ULF) divided by ten

Figure 20. Musculoskeletal diagnoses by gender and age group, 1971-2005

Finally, Figure 21 shows the development for mental disorders. The importance of mental disorders for DI incidence has been invariant or falling in all demographic groups until the late 1990s. This was followed by an enormous increase in the importance of mental disorders for granting disability benefits to women and a slight upturn for men. This increase is well reflected in the self-reported disease prevalence, except for men aged 60-64. Also the stable or falling trend in DI incidence before the 2000s corresponded to the development of selfreported disease prevalence, except for women aged 60-64. 
The utilization of inpatient care due to mental disorders shows no correspondence with diagnosis-specific DI incidence. Inpatient care utilization increased dramatically in the early 1970s and was then consistently falling over time. Such a consistent development might be due to changing working procedures in the healthcare system with this type of patients rather than an underlying trend in health. The mortality rate also shows no correspondence with the development of DI incidence. It should be noted, however, that the mortality rates in musculoskeletal diseases and mental disorders are extremely low and hence very dependent on diagnosing patterns.

A. Men age 55-59

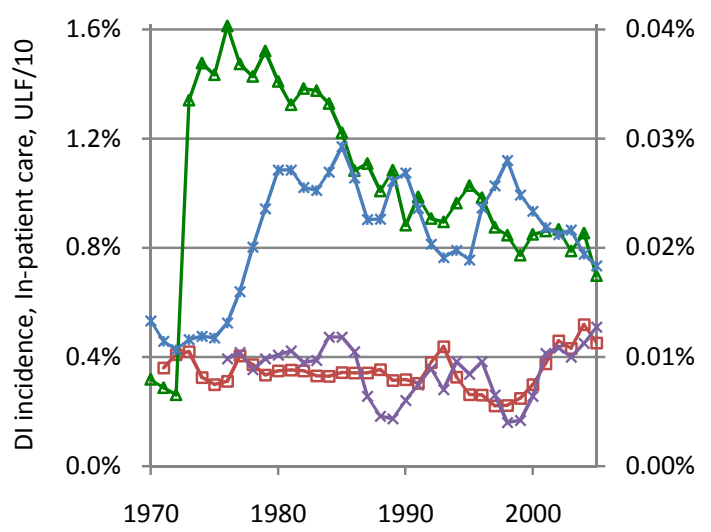

C. Men age $60-64$
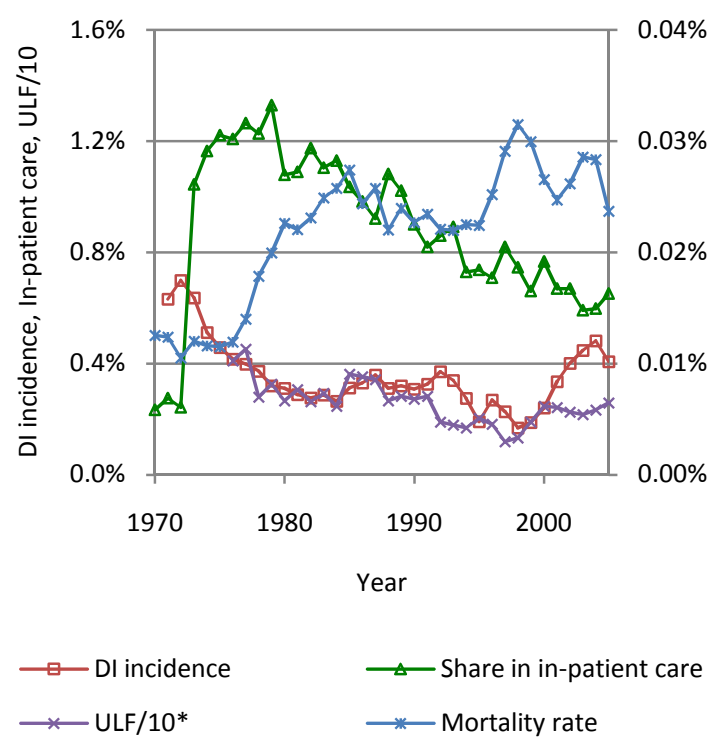

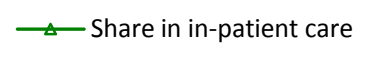

—-Mortality rate
B. Women age 55-59

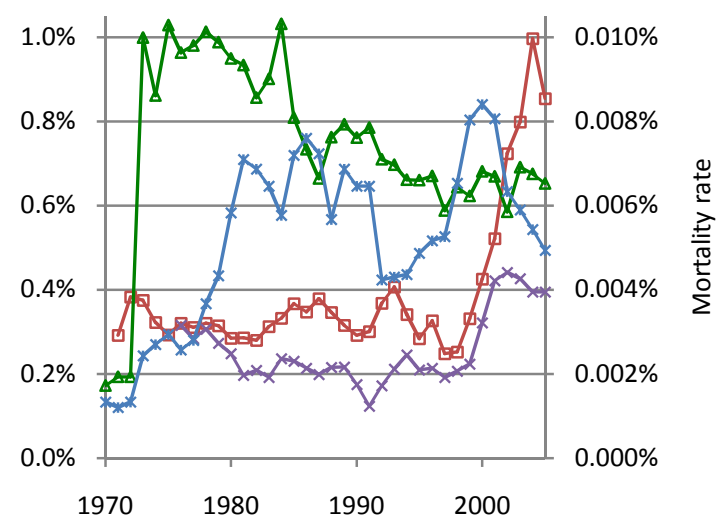

D. Women age 60-64
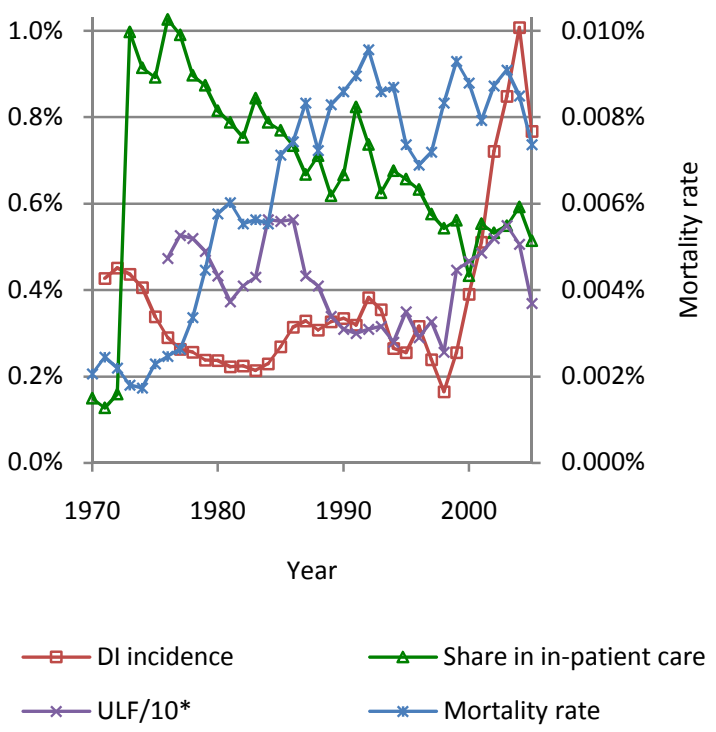

* ULF/10 = Share of the population reporting the particular disease in The Survey on Living Conditions (ULF) divided by ten

Figure 21. Mental disorders by gender and age group, 1971-2005 


\subsection{The relative health of disability insurance recipients to that of non-recipients}

An alternative way of examining the role of health for the development of disability insurance recipiency is to compare the health of disability insurance recipients with the health of nonrecipients. With a fixed health threshold for DI recipiency, we would expect the relative health of recipients relative to non-recipients to remain constant even if the prevalence of DI recipiency changes. If changes in the prevalence of DI recipiency are instead induced by for example economic incentives, less stringent health requirements for eligibility or a change in demand for workers with health-induced work limitations, we would expect the health of DI recipients relative to the health of non-recipients to improve as recipiency increases.

We divided the respondents in the Survey on Living Conditions into disability insurance recipients and non-recipients. Figure 22 shows the development of the relative health of DI recipients relative to non-recipients for nine self-reported health indicators from the survey along with the prevalence of DI recipiency. For each indicator, the relative measure shows the prevalence of a particular condition in the DI population as a fraction of the prevalence in the non-DI population. For example, the upper left-hand panel in Figure 22 shows that in 1976, a ten times larger proportion of those receiving disability benefits reported an impaired work capacity as compared to non-DI recipients. Due to sample size restrictions, the results are presented for the entire age group 45-64 year olds and the presented series are three-year moving averages. The left-hand panels show the development for men and the right-hand panels for women.

Figure 22 reveals much volatility, but no obvious trend, for the health of DI recipients relative to non-recipients before 1995. For men, most indicators remain constant also after 1995, although the share of men in poor health, the share with an impaired ability to move and the share who recently visited a doctor increase in the 2000s. This suggests, if anything, a worsened health of male DI recipients relative to non-recipients in recent years. For women, there is an opposite trend as that for men from 1995 to 2005. During this period, disability insurance recipiency for women increased substantially. The health indicators in panel B, showing the prevalence of impaired work capacity, impaired ability to move and poor health, show a downward trend since 1995. Also the prevalence of long-term disease in panel D has been falling, while the share of women with a self-reported good health has increased, for DI recipients relative to non-recipients. The share of women who visited a doctor, reported in 
panel F, fell at least initially as DI caseloads took off. This suggests a relative improvement in the health of female DI recipients as compared to non-recipients between 1995 and 2005.

\subsection{Conclusions about health and the disability insurance}

The analysis in this section showed that there is no relation between mortality and disability insurance recipiency in general in any age and gender group. This result does not, however, preclude that there is an underlying relation between population health and DI recipiency. As discussed in section 3, mortality might be a poor measure of the aspects of population health that are important for DI recipiency.

For the self-reported health indicators, there are some results indicating that population health indeed is an important determinant of disability insurance utilization. In particular, the share of the population with an impaired work capacity developed in a similar manner as the prevalence of DI recipiency. The health in younger age groups has declined compared to older groups, and the health of women has declined compared to men. This pattern is consistent with the development of disability insurance recipiency. From the analysis of the diagnosisspecific health indicators, we also saw a corresponding pattern between disability insurance incidence and the development of self-reported diagnosis-specific diseases.

The relation between health and disability insurance seems to be strongest for the younger age groups. For the age group 60-64, a potential relation between health and DI recipiency can be seen only from 1990 onwards. For men in this age group, the drop in DI recipiency during the last decade coincided with a drop in the share of the population with an impaired work capacity. For women in this age group, however, the development of disability insurance recipiency during the last decade seem to be less health related than for men. As DI recipiency increased, the health of disability insurance recipients relative to non-recipients improved. This implies that relatively healthier women than before started to receive disability benefits. 
A. Men age $45-64$

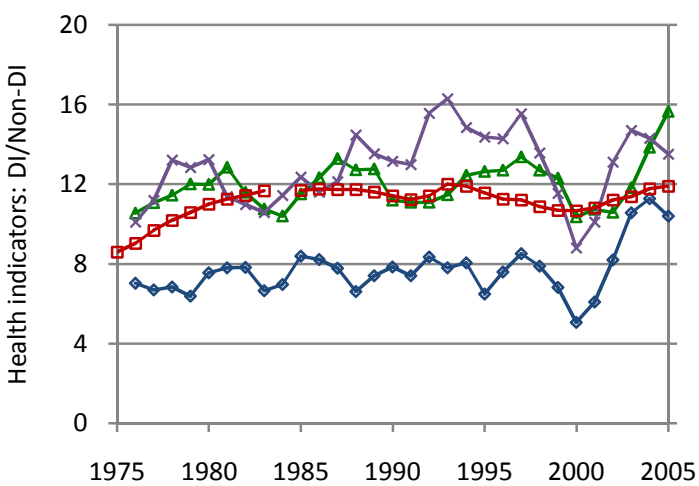

$\longrightarrow$ Impaired work capacity $\longrightarrow$ Poor health

$\longrightarrow$ Impaired ability to move $\longrightarrow$ DI prevalence

C. Men age $45-64$

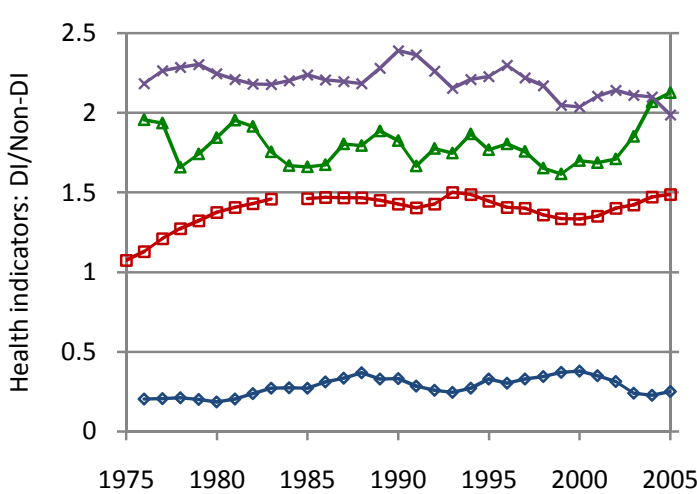

$\triangle$ Doctor's visitwithin 3 months $\longrightarrow$ Long-term disease

$\because$ Good health $\quad \longrightarrow$ DI prevalence

E. Men age 45-64

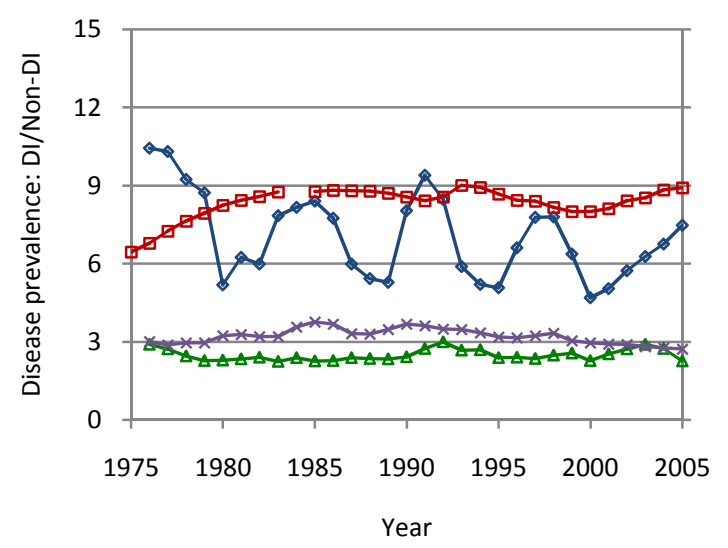

$\triangle$ Circulatory diseases $\quad *$ Musculoskeletal diseases

$\simeq$ Mental disorders
B. Women age $45-64$

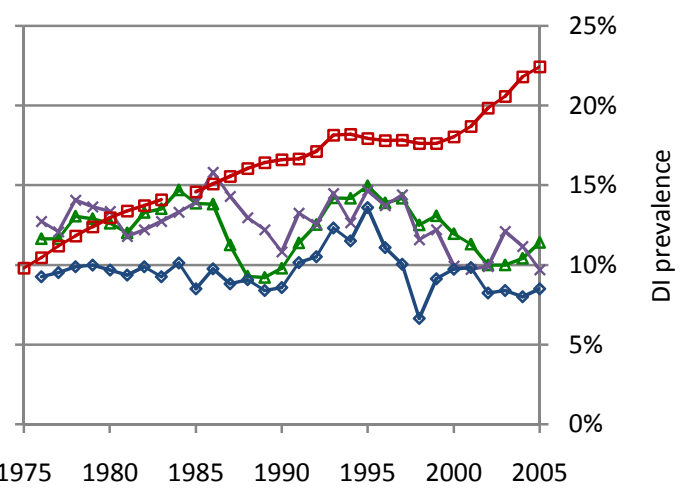

$\multimap$ Impaired work capacity $\longrightarrow$ Impaired ability to move
$\square$ Poor health

D. Women age 45-64
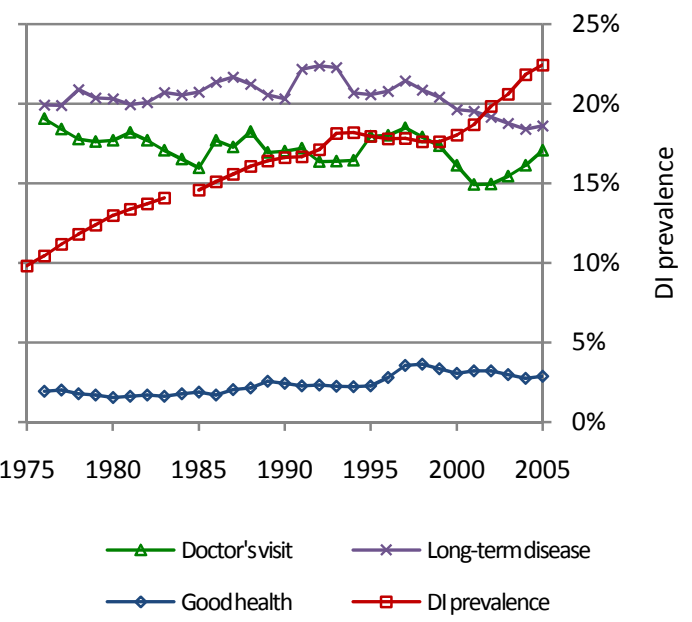

F. Women age 45-64

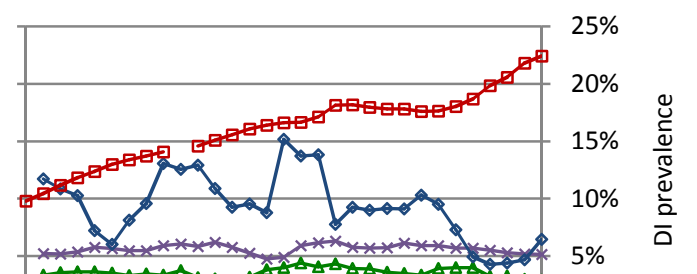

Figure 22. Relative health of DI recipients compared to non-DI recipients, 1975-2005

Sources: Survey on Living Conditions and the Swedish Social Insurance Agency 


\section{Changes in disability insurance eligibility}

The changes in the design of the disability insurance program in Sweden were described in Section 2 of this paper. Two major reforms in the history of the program were directed towards older workers only. First, special eligibility rules for older workers were introduced in 1970 and abolished in 1997. Second, a possibility of granting disability benefits based on pure labor market reasons for older workers was introduced in 1972 and abolished in 1991. The age limits were initially set to age 63-66, but was changed to 60-64 in 1974 for pure labor market reasons and in 1976 for the special eligibility rules.

The fact that the changes in eligibility affected a limited group only makes the implementation of these rules favorable from an evaluation point of view. It enables us to analyze the effect of changes in eligibility in a demographically defined group and use the younger age group aged 55-59 as an unaffected control group. In this section, we analyze the introduction of the special eligibility rules in 1970 and the pure labor market reasons in 1972 and the subsequent abolitions in 1997 and 1991. We analyze the impact of the eligibility reforms on disability insurance recipiency and study to what extent the reforms also affected labor market outcomes.

As described in section 2, also another set of eligibility rules were in effect between 1970 and 1997. These rules affected all workers, and implied that long-term unemployed with functional limitations were made eligible for disability benefits after having been unemployed for 1-2 years. Since these rules affected all workers, there is no control group to use in order to distinguish the effect of the rules from general time trends. When studying the effect of the special eligibility rules that were in effect during the same period, we implicitly assumes that the unemployment as an additional criterion for disability insurance eligibility affected the age groups 55-59 and 60-64 equally. If the unemployment criterion in fact was more important in the older age group than in the younger, the effect of these rules will be subsumed in the effect of the special eligibility rules for older workers.

As was also described in section 2, eligibility for disability insurance recipiency was recently changed again. Since 1 July 2008, an individual's working capacity has to be permanently reduced in relation to the entire labor market in order to qualify for disability benefits. Since this change affected all disability insurance applicants simultaneously, we cannot evaluate the 
impact of these changes in a control group setup. Figure 8 showed a substantial decrease in the incidence of disability insurance recipiency during the last years, and the decrease is particularly steep since 2008 .

\subsection{Program eligibility and disability insurance recipiency}

The upper panels in Figure 23 show the development of the prevalence of disability insurance recipiency for men and women, respectively. Vertical lines mark the introduction of the special eligibility rules for elderly workers in 1970 and the abolition of these rules in 1997, as well as the introduction of labor market reasons in 1972 and the subsequent abolition in 1991 . The lower panels in Figure 23 show the differences in disability insurance recipiency between the group aged 60-64 and the younger group aged 55-59. Figure 24 presents similar panels for the incidence of disability insurance recipiency, i.e. the admitted disability insurance recipients as a share of the risk population in each age group.

The upper panels in Figure 23 show a clear increase in the growth rate of DI recipiency after the 1970 reform. The increase in the growth rate is particularly large for the oldest age group. The lower panels show that the difference in DI prevalence between age groups 60-64 and 55-59 is fairly constant before 1970, at least for women, but increases rapidly after 1970. This indicates that there was an effect of the special eligibility rules for older workers that were introduced in 1970. Unfortunately, we do not have data on the incidence of disability insurance recipiency in these age groups before 1971. The number of entrants into DI in all ages, however, almost doubled from around 23000 in 1968 to around 44000 in 1970.

The next reform is the introduction of pure labor market reasons for older workers in 1972. It is not possible to perceive any effect of this reform on the growth rate of DI prevalence in Figure 23. From panels $\mathrm{E}$ and $\mathrm{F}$ in Figure 9, however, we know that pure labor market reasons accounted for an entry rate of around 1 percent of the risk population from its introduction until 1983. The lower panels in Figure 24 show the difference in the incidence of disability insurance recipiency between the age group 60-64 and 55-59. The difference is slightly larger in 1972 and 1973 than in 1971, which might indicate a small immediate effect of the 1972 reform on total DI entry rates. 
A. Male DI prevalence

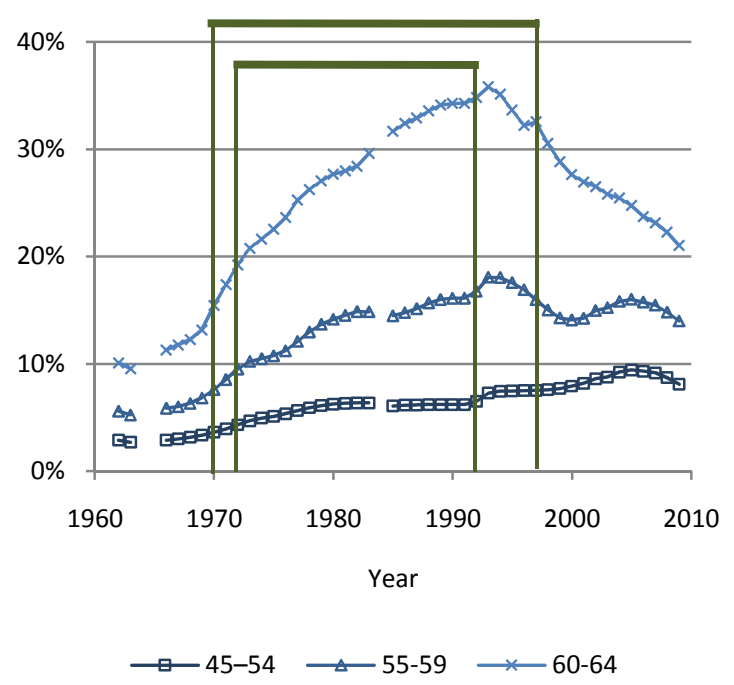

C. Difference in DI prevalence for men:

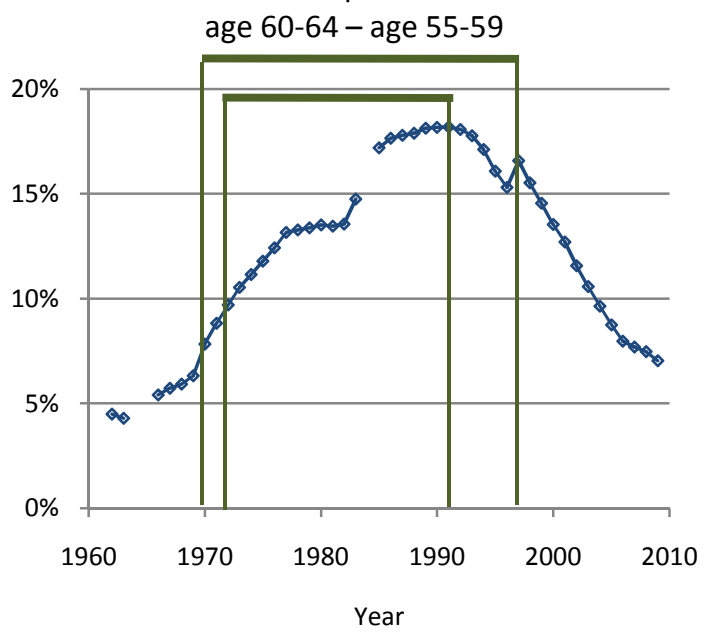

B. Female DI prevalence

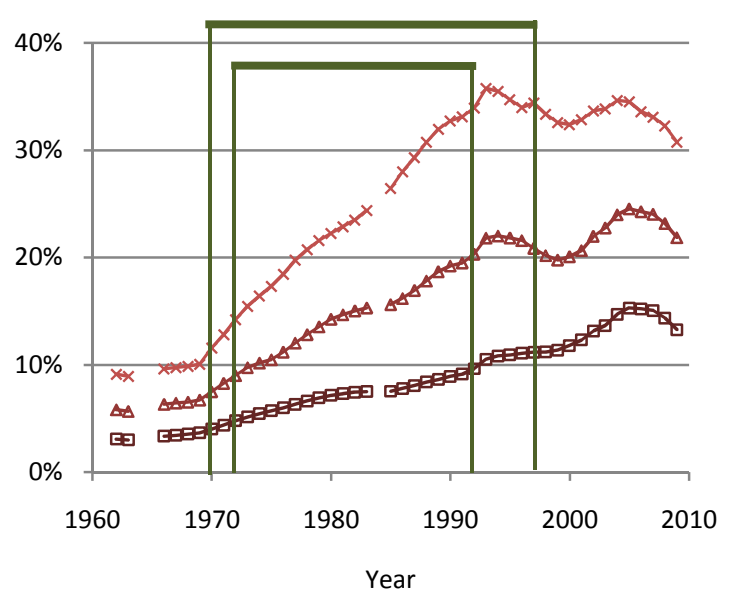

$\longrightarrow-45-54 \longrightarrow 55-59 \longrightarrow 60-64$

D. Difference in DI prevalence for women: age 60-64-age 55-59

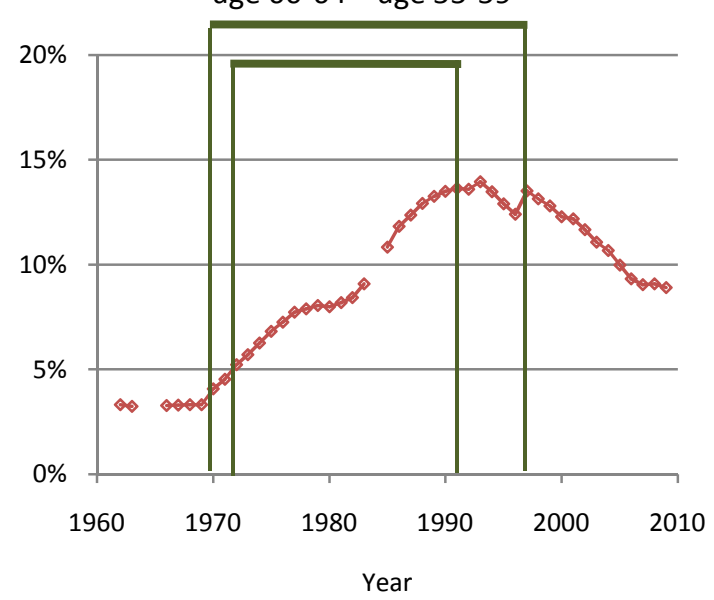

Figure 23. Prevalence of disability insurance utilization and the timing of DI reforms. Source: The Swedish Social Insurance Agency

As discussed in Section 4, there was a clear trend break in disability insurance recipiency in the older age groups in the early 1990s. This coincided with the abolishment of pure labor market reasons in 1991 and the rehabilitation reform in 1992. It also coincided, however, with a deep recession in Sweden. The upper panels of Figure 23 show this trend break in the prevalence of disability insurance recipiency in age groups 55-59 and 60-64. The increase in 1992 and 1993 is due to the fact that a large number of recipients of sickness benefits were transferred to the disability insurance program as a consequence of a rehabilitation reform affecting the work of the Social Insurance Agencies. 
A. Male DI incidence

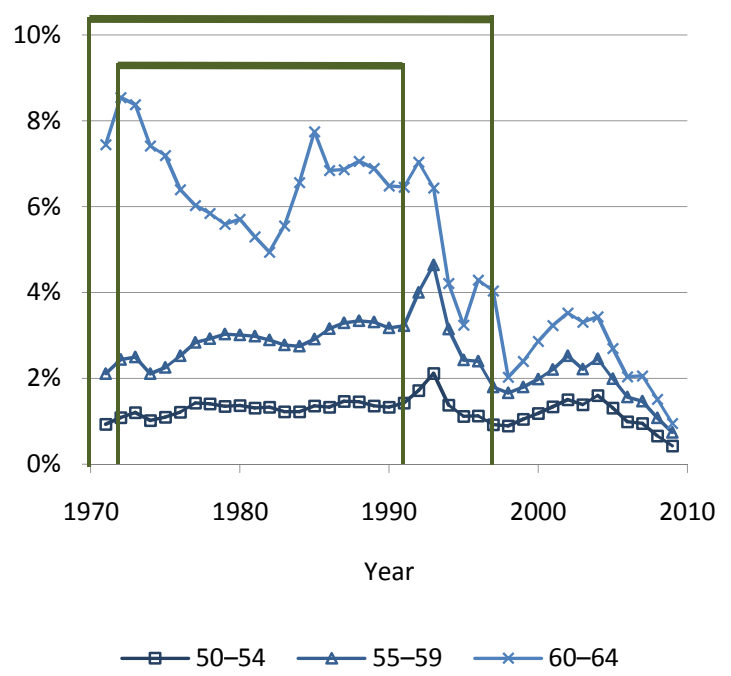

C. Difference in DI incidence for men:

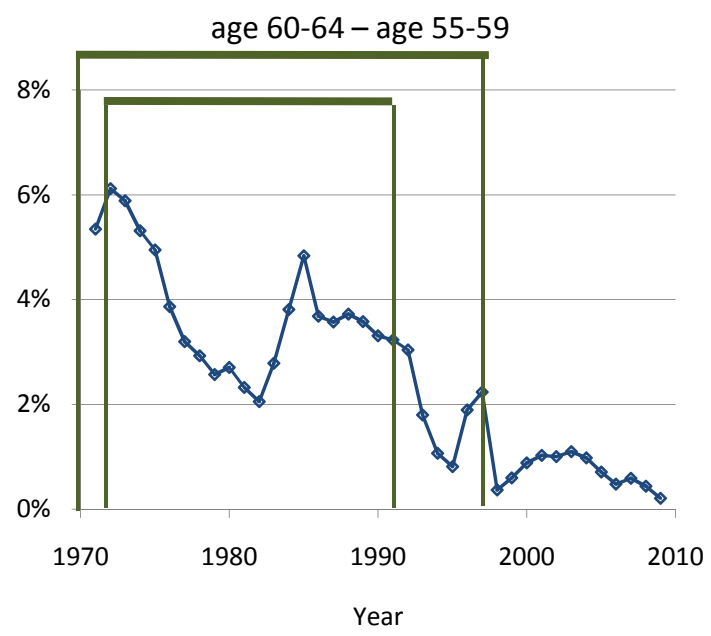

B. Female DI incidence

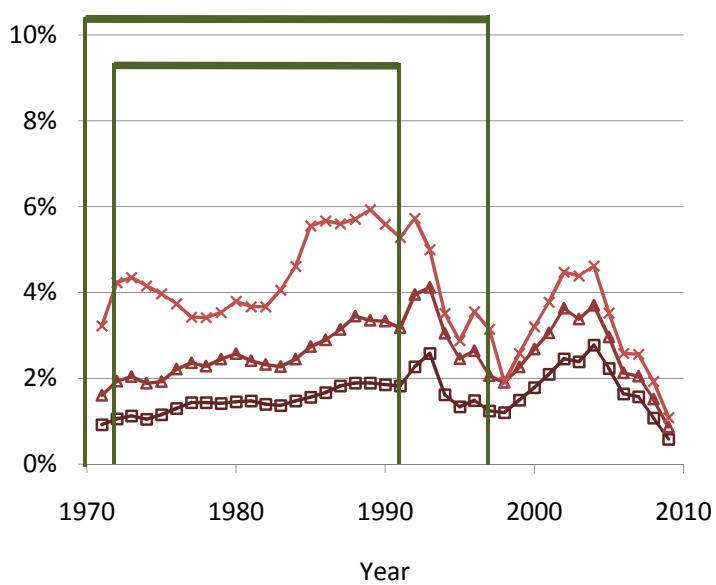

$\square-50-54 \longrightarrow 55-59 \longrightarrow 60-64$

D. Difference in DI incidence for women:

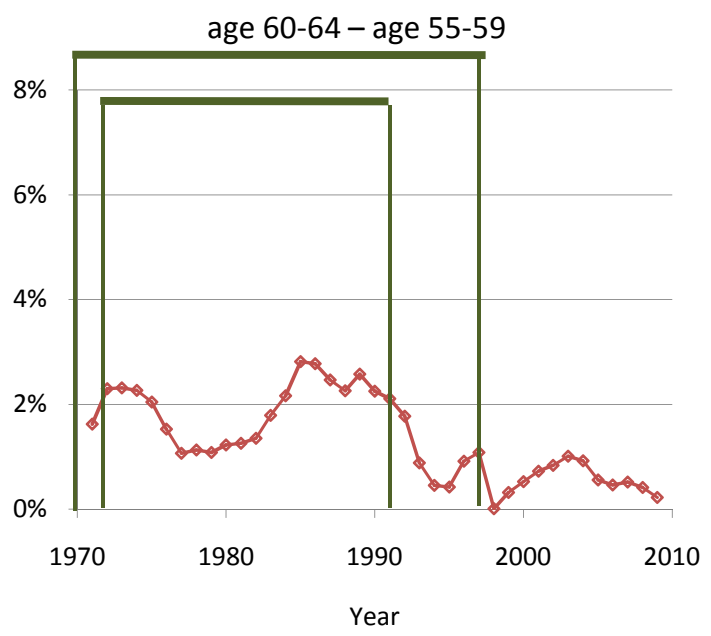

Figure 24. Incidence of disability insurance utilization and the timing of DI reforms Source: The Swedish Social Insurance Agency

The lower panels in Figure 24 show that the difference in disability insurance entry rates between age groups 60-64 and 55-59 was substantially lower after the 1991 reform than before. The abolishment of the pure labor market reasons for aged 60-64 in 1991 hence seems to have had an effect on disability insurance recipiency in the affected age group. The effect was larger for men than for women. Entry rates into disability insurance were higher for men before the reform, but of the same magnitude as for women after the reform. 
The abolishment of special eligibility rules for older workers in 1997 has been thoroughly analyzed in Karlström, Palme and Svensson (2008). According to their analysis, there is no significant effect on entry rates into the disability insurance. There is, however, a significant anticipation effect - an increase in entry rates into DI just before the reform - corresponding to almost 2 percent of the labor force in ages 60-64. Since the new eligibility rules were announced long before they were implemented, workers who believed they would pass the pre-reform eligibility rules, but not the post-reform ones, could apply under the pre-reform regime. This effect is seen in panels $C$ and $D$ in Figure 16 from the increase in the difference in DI entry rates during 1996 and 1997.

\subsection{Program eligibility and labor market outcomes}

The eligibility reforms for older workers seem to have had an effect on the utilization of the disability insurance. An extended question is to what extent these effects were translated into effects on employment and labor force participation rates. Figure 25 shows the development of disability insurance prevalence, non-labor force participation and non-employment for men and women aged 55-59 and 60-64. Figure 26 shows the difference in non-labor force participation and non-employment rates between the age groups 60-64 and 55-59, along with the corresponding difference for the prevalence and incidence of disability insurance recipiency. The reforms under study are marked with vertical lines.

The left-hand panels in Figure 25 show that the change in the prevalence of disability insurance recipiency after the reform in 1970 was indeed translated into a correspondingly large increase in non-employment and non-labor force participation for the male population in both age groups. Figure 26 shows that the differences in non-labor force participation and non-employment between the age groups 60-64 and 55-59 increased in the same manner as disability insurance recipiency during the 1970s. The pure labor market reasons, introduced in 1972, were not extensively used until the mid 1980s. When they were used, however, we do see an increase in non-employment and non-labor force participation that suggests a continuously close relationship between the prevalence of disability insurance recipiency and labor market outcomes also in the 1980s. For the 1970s and 1980s, the utilization of the disability insurance program hence seems to have translated into effects on non-employment and non-labor force participation rates. 

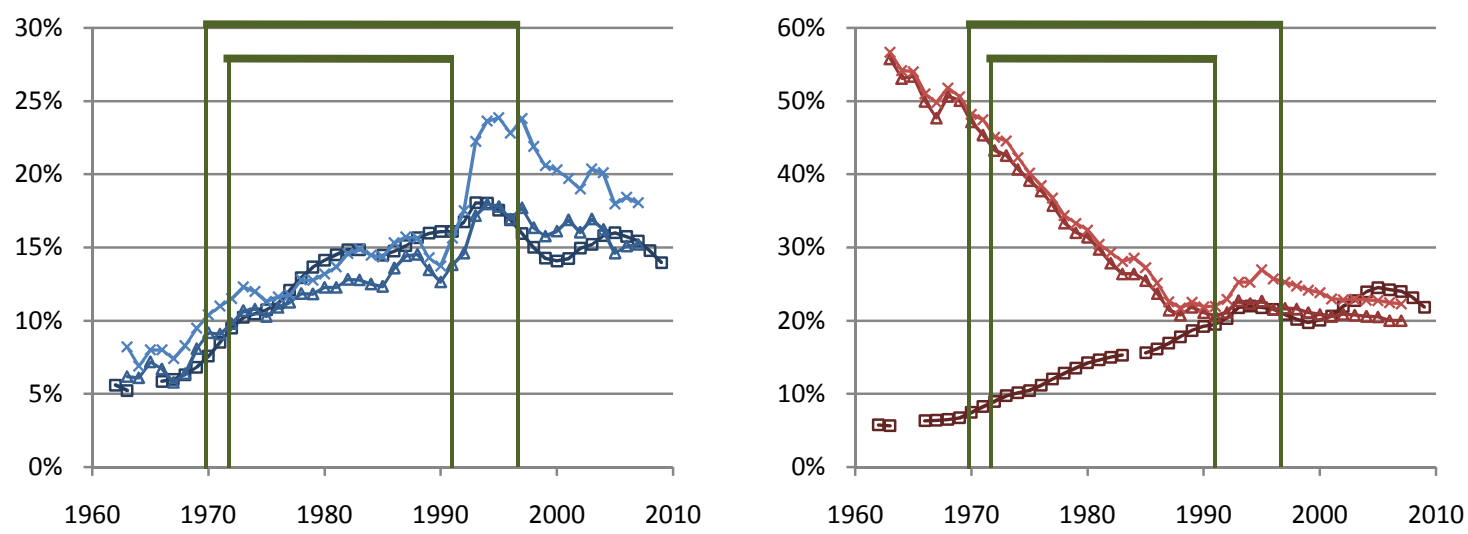

E. Men age 60-64

F. Women age 60-64
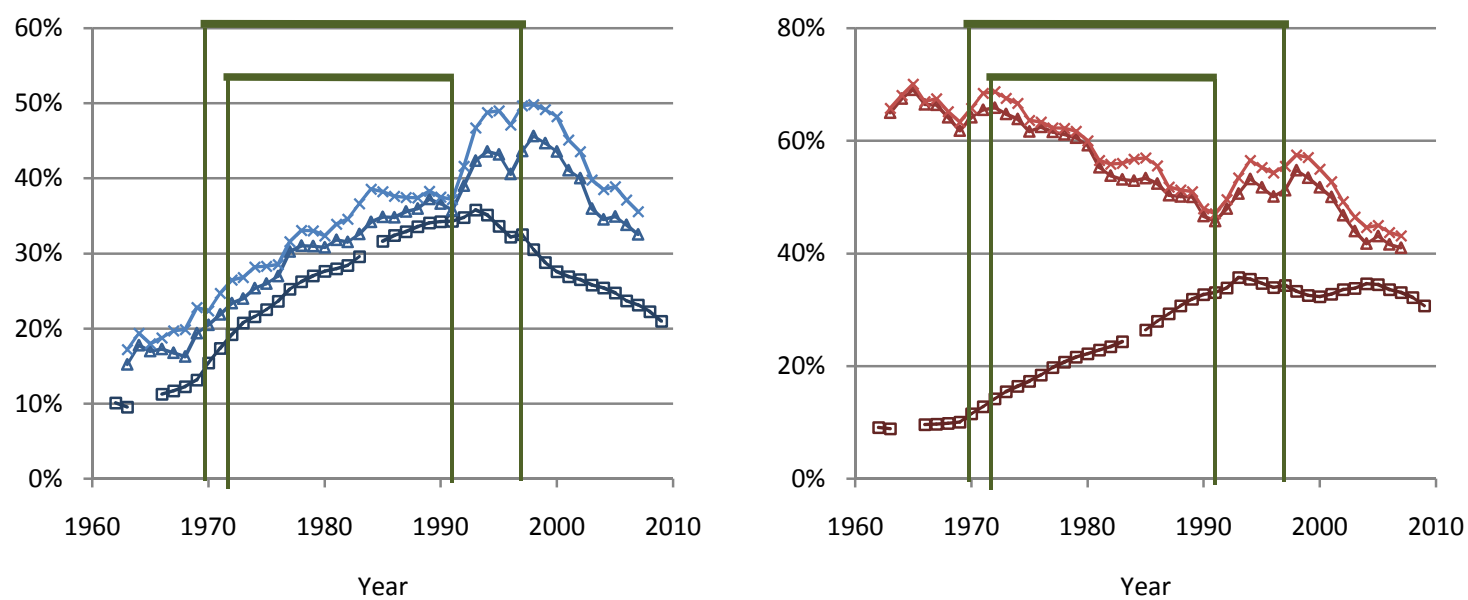

$\longrightarrow$ DI prevalence

$\triangle$ Non-labor force participation rate

$\simeq$ Non-employment rate

$\longrightarrow$ DI prevalence

$\longrightarrow$ Non-labor force participation rate

× Non-employment rate

Figure 25. DI prevalence, non-labor force participation and non-employment

The 1991 reform seems to have had a very different effect. While there was a rapid decrease in disability insurance recipiency, both non-employment and non-labor force participation increased in the age group 60-64. In the age group 55-59, the decrease in disability insurance recipiency coincided with an increase in non-employment, but not in non-labor force participation. The background to this result might be the deep economic recession in the early 1990s which resulted in a sharp decrease in labor demand. As concluded in section 4, disability benefits were replaced by income from unemployment benefits, occupational pension and sickness benefits. 
A. Men

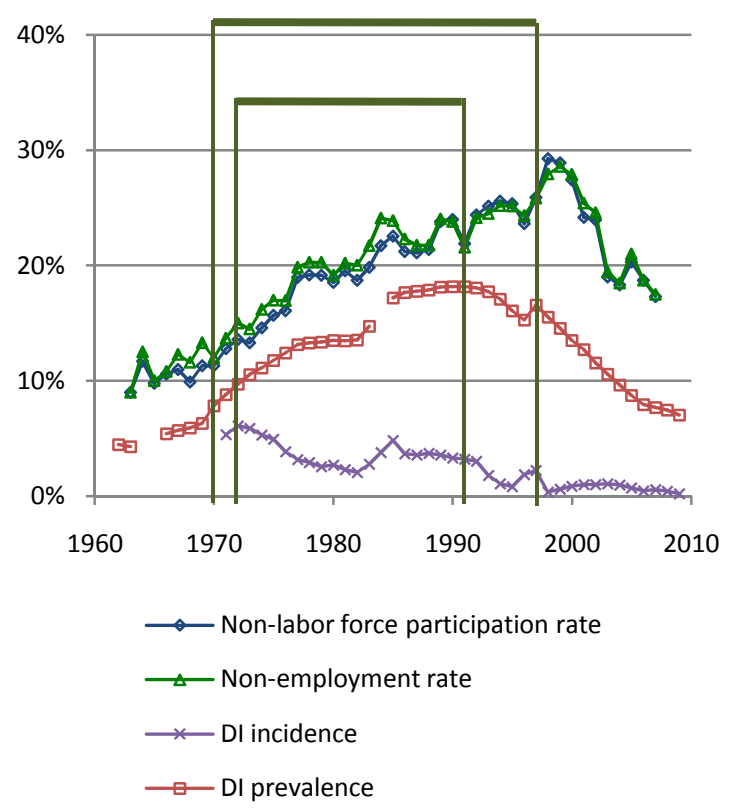

B. Women

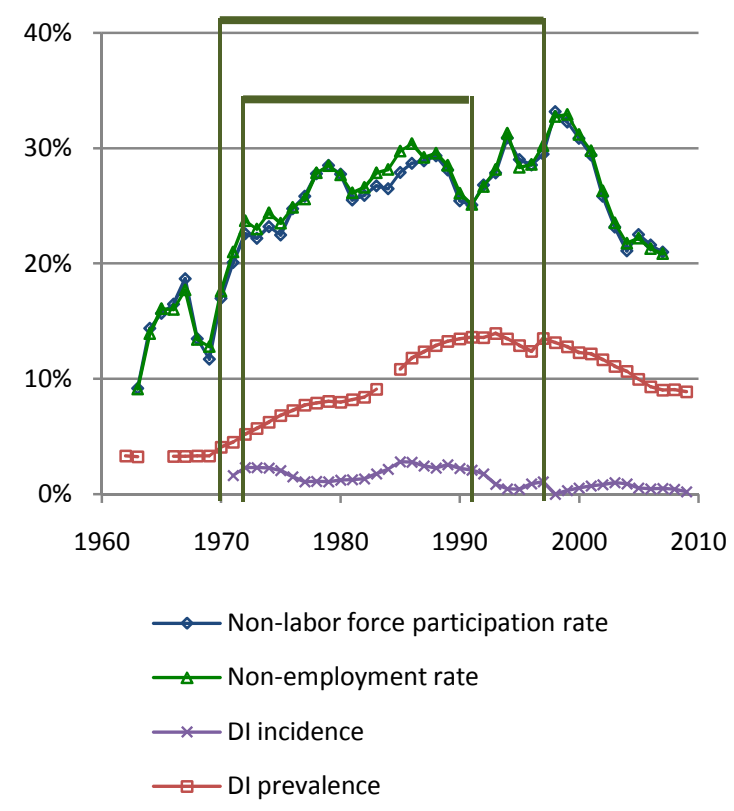

Figure 26. Differences between age groups 60-64 and 55-59

Contrary to the 1991 reform, Figure 26 suggests that the abolition of the special eligibility rules for workers aged 60-64 in 1997 was followed by increased employment and labor force participation. A detailed analysis of the effects of this reform on employment and on the utilization of the sickness and unemployment insurance programs is found in Karlström, Palme and Svensson (2008). They did not, however, find a significant effect of the reform on employment, but did find an effect on both entry and persistence in the unemployment and sickness insurance programs (not considered in Figures 25 and 26). Their conclusion is that the other income security programs worked like communicating vessels that crowded out the employment effect of the stricter eligibility rules enacted in the 1997 reform. Looking closer at Figure 26, the decrease in non-employment and non-labor force participation did not come until a few years after this reform. It is therefore difficult to attribute the drop to the reform itself.

\subsection{Conclusions about program eligibility, disability insurance and labor market outcomes}

Our analysis of the changes in the eligibility rules shows that the introduction of special eligibility rules for older workers in 1970 seems to have had an effect on the utilization of the disability insurance and that the effect translated into effects on labor force participation and 
employment. We did not find support for an additional effect of the introduction of pure labor market reasons for older workers in 1972 on disability insurance recipiency. The pure labor market reasons were not being used extensively until the early and mid 1980s. At that time, however, there is also an increase in non-employment and non-labor force participation.

For the 1990 and 1997 reforms, the analysis shows that the marked change in utilization of the disability insurance was "crowded out" by changes in the utilization of other income security programs. However, the long term relative increase in employment and labor force participation of the age group 60-64 among both males and females after 1997 suggests that there was an effect of the 1997 in prolonging the time before the permanent exit from the labor market of older workers.

\section{Overall conclusions}

In this paper, we posed three main research questions. The first question was whether the development of disability insurance recipiency over the past decades can be explained by changes in the health status of the population. We found some support for this hypothesis. We focused on the development for men and women in the age groups 45-54, 55-59 and 60-64. The analysis showed that the demographic groups with the least advantageous health development were the same groups with the least advantageous development in disability insurance recipiency. In particular, we found a more adverse development of the health of women compared to men, and the health of younger compared to older. The same pattern can be found in the development of disability insurance recipiency. The relation between population health and disability insurance recipiency was least apparent for the oldest age group, aged 60-64.

The second question was whether the changes in disability insurance recipiency can be explained by changes in the eligibility rules in the disability insurance program. We focused on the introduction and abolishment of two sets of eligibility rules that affected the oldest age group, aged 60-64, only. The first were the special eligibility rules for older workers, implying an exempt from rehabilitation and retraining, lowered requirements for the medical assessment of working capacity and a possibility to consider functional limitations due to normal aging for eligibility to disability benefits. The second was the introduction of pure 
labor market reasons for older workers, making them eligible for disability benefits if they were still unemployed when reaching the time limit for unemployment benefits. The special eligibility rules for older workers were in effect between 1970 and 1997, while the pure labor market reasons were in effect between 1972 and 1991.

For some of the changes in eligibility for older workers, we found evidence of an effect on disability insurance recipiency. The introduction of the special eligibility rules in 1970 seems to have had a large impact on disability insurance recipiency. The introduction of pure labor market reasons in 1972, however, seems to have induced only a small additional increase in the entry rates into the disability insurance program. The abolishment of the pure labor market reasons in 1991 seems to have had a larger effect on disability insurance recipiency. The abolishment of the special eligibility rules for older workers in 1997 did affect disability insurance recipiency but the effect on employment was crowded out by an increased utilization of the sickness and unemployment insurances. In the long run, however, the difference in non-employment rates between the age groups 60-64 and 55-59 has been decreasing after the reform, which might suggest that the eligibility changes in the disability insurance in 1997 eventually spilled over on employment.

The final question was to what extent the changes in eligibility rules for older workers affected employment and labor force participation. The answer is ambiguous. For the 1970 reform, this seems to be true in the sense that the reform opened the disability insurance program as a much more frequent exit route from employment than before. In fact, the disability insurance program became almost the only pathway out of the labor force before the normal retirement age in the decades following the reform. The results are complicated to analyze for the 1991 and 1997 reforms. The 1991 reform coincided with a sharp drop in the employment rate, caused by a labor demand shock from a severe recession. The conclusion for the 1997 reform is that it did not lead to a significant increase in employment. The effect on the disability insurance utilization was crowded out by an increase in the unemployment rate and increased utilization of the sickness insurance. However, several years after the reform, we have seen significant improvements in employment rates among older workers. It is an open question to what extent the new regime within the disability insurance after 1997 contributed to this development. 
There are several significant changes in the usage of disability benefits that cannot be directly related to either changes in health or reforms of the rules of the program. Throughout the many graphs shown in this paper we have seen that trends tend to continue, without visible changes in eligibility rules or population health. Possible explanations are (1) changes in the demand for labor with health impairments; (2) formation of norms on eligibility to disability insurance in the social security administration and in the society in general; (3) administrative policies within the social insurance system; or (4) changes in economic incentives the disability insurance program primarily attributed to maturation of the supplementary pension program (the ATP system). The relative importance of these factors is a subject for further research in this area. 


\section{References}

Gruber, Jonathan and David A. Wise (2010) Social Security and Retirement Around the World: The Relationship to Youth Employment, Chicago: The University of Chicago Press.

Hedström, Peter (1987) “Disability Pension: Welfare or Misfortune?” International Journal of Sociology, 87, 1261-1284.

Karlström, Anders, Mårten Palme and Ingemar Svensson (2008) “The Employment Effect of Stricter Rules for Eligibility to DI: Evidence from a Natural Experiment in Sweden” Journal of Public Economics, 2008, 92, 2071-2082.

Kruse, Agneta and Lars Söderström (1989) "Early Retirement in Swden”. In Redefining the Process of Retirement, ed. W. Schmäl. Berlin: Springer.

Lindbeck, Assar, Mårten Palme and Mats Persson (2009) "Social Interaction and Sickness Absence", Working Paper 2009:4. Department of Economics, Stockholm University.

Palme, Mårten and Ingemar Svensson (1999) "Social security, occupational pensions and retirement in Sweden". In J. Gruber and D. Wise (eds.), Social Security and Retirement Around the World. Chicago: The University of Chicago Press.

Palme, Mårten and Ingemar Svensson (2004) "Income Security Programs and Retirement in Sweden”. In J. Gruber and D. Wise (eds.) Social Security and Retirement Around the World: Micro-estimates, 2004, Chicago University Press: Chicago.

Statistics Sweden (2009) “Undersökning om levnadsförhållanden 2009”. Available at http://www.scb.se/Statistik/LE/LE0101/_dokument/LE0101_DO_2009.pdf.

Skogman Thoursie, Peter (1999) "Disability and work in Sweden", Ph.D. thesis. Swedish Institute for Social Research, no. 39, Stockholm.

Wadensjö, Eskil (1996) "Early Exit from the Swedish Labour Market". In E. Wadensjö (ed.), The Nordic Labour Markets in the 1990's. North-Holland: Amsterdam. 